pag

Business School

WORKING PAPER SERIES

\begin{tabular}{l|l} 
Working Paper & $\begin{array}{l}\text { Policy-oriented macroeconomic } \\
\text { forecasting with hybrid DGSE and } \\
\text { time-varying parameter VAR models }\end{array}$ \\
$2014-426$ & $\begin{array}{l}\text { Stelios D. Bekiros } \\
\text { Alessia Paccagnini }\end{array}$
\end{tabular}

http://www.ipag.fr/fr/accueil/la-recherche/publications-WP.html

IPAG Business School

184, Boulevard Saint-Germain

75006 Paris

France 


\title{
Policy-oriented macroeconomic forecasting with hybrid DGSE and time-varying parameter VAR models *
}

\author{
Stelios D. Bekiros ${ }^{\dagger}$ \\ Athens University of Economics and Business (AUEB), Department of Finance \\ 76 Patission str, GR104 34, Athens, Greece \\ $\&$ \\ European University Institute (EUI), Department of Economics, Via della Piazzuola
}

43, I-50133, Florence, Italy

\author{
Alessia Paccagnini ${ }^{\ddagger}$ \\ Università degli Studi di Milano-Bicocca, Department of Economics, \\ Piazza Ateneo Nuovo 1, 20126 Milano, Italy
}

\begin{abstract}
Micro-founded dynamic stochastic general equilibrium (DSGE) models appear to be particularly suited for evaluating the consequences of alternative macroeconomic policies. Recently, increasing efforts have been undertaken by policymakers to use these models for forecasting, although this proved to be problematic due to estimation and identification issues. Hybrid DSGE models have become popular for dealing with some of model misspecifications and the trade-off between theoretical coherence and empirical fit, thus allowing them to compete in terms of predictability with VAR models. However, DSGE and VAR models are still linear and they do not consider time-variation in parameters that could account for inherent nonlinearities and capture the adaptive underlying structure of the economy in a robust manner. This study conducts a comparative evaluation of the out-of-sample predictive performance of many different specifications of DSGE models and various classes of VAR models, using datasets for the real GDP, the harmonized CPI and the nominal short-term interest rate series in the Euro area. Simple and hybrid DSGE models were implemented including DSGE-VAR and Factor Augmented DGSE, and tested against standard, Bayesian and Factor Augmented VARs. Moreover, a new state-space time-varying VAR model is presented. The total period spanned from 1970:1 to 2010:4 with an out-of-sample testing period of 2006:1-2010:4, which covers the global financial crisis and the EU debt crisis. The results of this study can be useful in conducting monetary policy analysis and macro-forecasting in the Euro area.
\end{abstract}

JEL Classification: C11, C15, C32

Keywords: Model validation, Forecasting, Factor Augmented DSGE, Time-varying parameter VAR, DGSE-VAR, Bayesian analysis

*This paper has been presented at the Federal Reserve Bank of Philadelphia, at Ca' Foscari University of Venice, at the International Conference 2011 (Catholic University, Milan), at the 18th International Conference Computing in Economics and Finance (CEF 2012, Prague, Czech Republic) and at the CEPR-EABCN Conference at the Banque Central du Luxembourg (2012). We are grateful to Monica Billio, Satyajit Chatterjee, Diego Fresoli, Paolo Gelain, Matthias Kredler, Keith Kuester, Marcella Lucchetta, Leonard Nakamura, Giacomo Pansini, Gert Peersmann, Raffaele Rossi and Frank Schorfheide for valuable comments and discussions. The first author was supported in part by the Marie Curie Intra European Fellowship (FP7-PEOPLE2009-IEF, N²51877) under the 7th European Community Framework Programme. The second author acknowledges financial support from "Dote ricercatori": FSE, Regione Lombardia. The usual disclaimers apply.

${ }^{\dagger}$ Tel.: +39-055-4685-916; Fax: +39-055-4685-902; email: stelios.bekiros@eui.eu

‡Tel.: +39-026-4483-046; Fax: +39-026-4483-085; email: alessia.paccagnini@unimib.it 


\section{Introduction}

The development of dynamic stochastic general equilibrium (DSGE) models that build on explicit microfoundations with optimising agents was witnessed in recent years. Major advances in estimation methodology provided with various specifications of these models that are able to compete, in terms of data fit and predictability with more standard time-series models, such as vector autoregressions. The new micro-founded DSGE models appear to be particularly suited for evaluating the consequences of alternative macroeconomic policies, as shown in the works of Smets and Wouters (2003, 2004), Del Negro and Schorfheide (2004), Adolfson et al. (2008) and Christiano et al. (2005). Model validation using DSGE models allows the econometrician to establish a link between structural features of the economy and reduced form parameters, which was not always possible with the usual large-scale macroeconomic models. The combination of rich structural models, novel solution algorithms and powerful simulation techniques has allowed researchers to develop the so-called "New Macro-econometrics" (Fernandez-Villaverde, 2009). However, the calibrated DSGE models are typically too stylized to be taken directly to the data and often yield weak results (Stock and Watson, 2001; Ireland, 2004). As reported in Schorfheide (2010), DSGEs face many important challenges such as the fragility of parameter estimates, statistical fit and the weak reliability of policy predictions. Sometimes DSGE models exhibit nonlinearities, even if the common practice is to solve and estimate a linearized version with Gaussian shocks. In addition, a number of papers report the lack of volatility modeling or parameter drifts using ad-hoc DSGE models applied to the Great Moderation period such as Kim and Nelson (1999), McConnell and Pérez-Quirós (2000), Clarida et al. (2000), Lubik and Schorfheide (2004), Canova and Gambetti (2004), Primiceri (2005), Cogley and Sargent (2005), Sims and Zha (2006), Justiniano and Primiceri (2008) and Benati and Surico (2009).

Increasing efforts have been undertaken to use these models also for forecasting. DSGE models were not considered as forecasting tools until the works of Smets and Wouters $(2003,2004)$ on the predictability of DSGE models compared to alternative non-structural models. In the macro-econometric literature, hybrid or mixture DSGE models have become popular for dealing with some of the model misspecifications as well as the trade-off between theoretical coherence and empirical fit (Schorfheide, 2010). They are categorized in additive hybrid models and hierarchical hybrid models. The hybrid models provide a complete analysis of the data law of motion and better capture the dynamic properties of the DSGE models. In the recent literature, different attempts of hybrid models have been introduced for solving, estimating and forecasting with DSGEs. Sargent (1989) and Altug (1989) proposed augmenting a DSGE model with measurement error terms that follow a first order autoregressive process, known as the DSGE-AR approach. Ireland (2004) proposed a method that is similar to the DSGE-AR, but imposing no restriction on the measurement errors, assuming that residuals follow a first-order vector autoregression (DSGE-AR à l'Ireland). A different approach called DSGE-VAR was proposed by Del Negro and Schorfheide (2004) and was based on the works DeJong et al. (1996) and Ingram and Whiteman (1994). The main idea behind the DSGE-VAR is the use of the VAR representation as an econometric tool for empirical validation, combining prior information derived from the DSGE model in estimation. However, it has several problems. One of the main problems in finding a statistical representation for the data by using a VAR, is overfitting due to the inclusion of too many lags and too many variables, some of which may be insignificant. The problem of overfitting results in multicollinearity and loss of degrees of freedom, leading to inefficient estimates and large out-of-sample forecasting errors. It is possible to overcome this problem by using the well-known "Minnesota" priors (Doan et al., 1984). The use of "Minnesota" priors has been proposed to shrink the parameters space and thus overcome the curse of dimensionality. Following this idea in combining the DSGE model information and the VAR representation, two alternative econometric tools have been also introduced: the DSGE-FAVAR (Consolo et al., 2009) and the Augmented VAR-DSGE model (Fernández-de-Córdoba and Torres, 2010). The main idea behind the Factor Augmented DSGE (DSGE-FAVAR) is the use of factors to improve the statistical identification in validating the models. Consequently, the VAR representation is replaced by a FAVAR model as the statistical benchmark.

So far, DSGE models ignore stochastic volatility and parameter drifts, and they only consider linear properties and no time-variation in parameters. However, the same applies to standard vector autoregressive (VAR) modelling introduced by Sims (1980). Even though the VAR model is proven to be a reliable forecasting tool, the classical VAR modelling fails to take into account the inherent nonlinearities of the economy. In these cases, time-varying parameters seem to be attractive alternatives. Time varying autoregressive (TVP- 
VAR) models have been developed since the early 1980's (Prado and West, 2001). The TVP-VAR model enables capturing a possible time-varying nature of underlying structure in the economy in a flexible and robust manner. Time varying VAR models led to new methods of time series decomposition and analysis as presented with applications in Primiceri (2005). Dahlhaus (1997, 2000) developed asymptotic estimators and results.

In this study, we conduct an exhaustive empirical exercise that includes the comparison of the out-ofsample predictive performance of estimated DSGE models with that of standard VARs, Bayesian VARs and Factor Augmented VARs estimated on the same data set for the Euro area economy. We focus on many different specifications of the DSGE models, i.e., the simple DSGE, the DSGE-VAR and specifically on the Factor Augmented DSGE (DSGE-FAVAR) model. Moreover, a new time-varying multivariate state-space estimation method for TVP-VAR processes is presented. The state space model has been well studied by Harvey (1990) and Durbin and Koopman (2002). For the TVP-VAR model, the parameters are estimated using a multivariate specification of the standard Kalman filter (Harvey, 1990), while the likelihood estimation is performed with a suitable multivariate extension of the Kim and Nelson (1999) method. We are also interested in the forecastability of the new TVP-VAR model in comparison to the DSGE class and the other VAR models. We use time series data from 1970:1 to 2010:4 for the real GDP, the harmonized CPI and the nominal short-term interest rate and we produce their forecasts for the out-of-sample testing period 2006:12010:4. The motivation comes from a group of recent papers that compares the forecasting performance of DSGE against VAR models. This includes Smets and Wouters (2004), Ireland (2004), Del Negro and Schorfheide (2004), Del Negro et al. (2007), Adolfson et al. (2008), Christoffel et al. (2008), Rubaszek and Skrzypczynski (2008), Ghent (2009), Kolosa et al. (2009), Consolo et al. (2009), Fernandez-de-Cordoba and Torres (2010), among others. The investigated time period includes the financial crisis of 2007-2009 and the EU debt crisis starting in early 2010, associated with the widening of bond yield spreads and the rise of credit default swaps, concerning Eurozone countries such as Greece, Ireland, and Portugal. The empirical validation included in the present study attempts to infer on whether the estimated models can be used for monetary policy analysis and macro-variable forecasting in the Euro area.

The remainder of this paper is organized as follows. Section 2 describes the standard and Bayesian VAR as well as the Factor Augmented VAR model. In section 3 the simple DSGE model is analyzed, and the hybrid DSGE-VAR and DSGE-FAVAR models are described in detail. Section 4 presents the time-varying multivariate state-space TVP-VAR model. In section 5 the data are described and the empirical results of the comparative forecasting evaluation are illustrated and analyzed. Finally, section 6 concludes.

\section{VAR Models}

\subsection{Classical VAR}

As suggested by Sims (1980), the standard unrestricted VAR, has the following compact format

$$
\mathbf{Y}_{t}=\mathbf{X}_{t} \boldsymbol{\Phi}+\mathbf{U}
$$

where $\mathbf{Y}_{t}$ is a $(T \times n)$ matrix with rows $Y_{t}^{\prime}$, and $\mathbf{X}$ is a $(T \times k)$ matrix $(k=1+n p, p=$ number of lags $)$ with rows $X_{t}^{\prime}=\left[1, Y_{t-1}^{\prime}, \ldots, Y_{t-p}^{\prime}\right]$. $\mathbf{U}$ is a $(T \times n)$ matrix with rows $u_{t}^{\prime}, \mathbf{\Phi}$ is a $(k \times n)=\left[\Phi_{0}, \Phi_{1}, \ldots, \Phi_{p}\right]^{\prime}$, while the one-step ahead forecast errors $u_{t}$ have a multivariate $N\left(0, \Sigma_{u}\right)$ conditional on past observations of $Y$.

\subsection{Bayesian VAR}

The Bayesian VAR, as described in Litterman (1981), Doan et al. (1984), Todd (1984), Litterman (1986) and Spencer (1993) has become a widely popular approach to dealing with overparameterization. One of main problems in using VAR models is that many parameters need to be estimated, although some of them may be insignificant. Instead of eliminating longer lags, the BVAR imposes restrictions on these coefficients by assuming that they are more likely to be near zero than the coefficients on shorter lags. Obviously, if there are strong effects from less important variables, the data can counter this assumption. Usually, the restrictions are imposed by specifying normal prior distributions with zero means and small standard deviations for all coefficients, with a decreasing standard deviation as the lags increase. The only exception is the coefficient on a variable's first lag that has a mean of unity. Litterman (1981) used a diffuse prior for the constant. The 
means of the prior are popularly called the "Minnesota Priors" due to the development of the idea at the University of Minnesota and the Federal Reserve Bank at Minneapolis ${ }^{1}$.

Formally speaking, these prior means can be written as follows

$$
\Phi_{i} \sim N\left(1, \sigma_{\Phi_{i}}^{2}\right) \text { and } \Phi_{j} \sim N\left(0, \sigma_{\Phi_{j}}^{2}\right)
$$

where $\Phi_{i}$ denotes the coefficients associated with the lagged dependent variables in each equation of the VAR, while $\Phi_{j}$ represents any other coefficient. The prior variances $\sigma_{\Phi_{i}}^{2}$ and $\sigma_{\Phi_{j}}^{2}$ specify the uncertainty of the prior means, $\Phi_{i}=1$ and $\Phi_{j}=0$, respectively. The specification of the standard deviation of the distribution of the prior imposed on variable $j$ in equation $i$ at lag $m$, for all $i, j$ and $m$, denoted by $S(i, j, m)$, is specified as follows

$$
S(i, j, m)=[w \times g(m) \times F(i, j)] \frac{\hat{\sigma}_{i}}{\hat{\sigma}_{j}}
$$

where

$$
F(i, j)=\left\{\begin{array}{c}
1 \text { if } i=j \\
k_{i j} \text { otherwise, } 0 \leq k_{i j} \leq 1
\end{array}\right.
$$

is the tightness of variable $j$ in equation $i$ relative to variable $i$ and by increasing the interaction, i.e. it is possible for the value of $k_{i j}$ to loosen the prior (Dua and Ray, 1995). The ratio $\frac{\hat{\sigma}_{i}}{\hat{\sigma}_{j}}$ consists of estimated standard errors of the univariate autoregression, for variables $i$ and $j$. This ratio scales the variables to account for differences in the units of measurement, without taking into account the magnitudes of the variables. The term $w$ measures the standard deviation on the first lag, and also indicates the overall tightness. A decrease in the value of $w$ results in a tighter prior. The function $g(m)=m^{-d}, d>0$ is the measurement of the tightness on lag $m$ relative to lag 1 , and is assumed to have a harmonic shape with a decay of $d$, which tightens the prior on increasing lags. Following the standard Minnesota prior settings, we choose the overall tightness $(w)$ to be equal to 0.3 , while the lag decay $(d)$ is 1 and the interaction parameter $\left(k_{i j}\right)$ is set equal to 0.5 .

\subsection{Factor Augmented VAR}

A recent strand in the econometric literature mainly by Stock and Watson (2002), Forni and Reichlin (1996, 1998) and Forni et al. $(1999,2000)$ has shown that very large macroeconomic datasets can be properly modelled using dynamic factor models, where the factors can be considered as an "exhaustive summary of the information " in the data. The rationale underlying dynamic factor models is that the behavior of several variables is driven by few common forces, the factors, plus idiosyncratic shocks. Hence, the factors-approach can be useful in alleviating the omitted variable problem in empirical analysis using traditional small-scale models. Bernanke and Boivin (2003) and Bernanke et al. (2005) utilized factors in the estimation of VAR to generate a more general specification. Chudik and Pesaran (2011) illustrated how a VAR augmented by factors could help in keeping the number of estimated parameters under control without loosing relevant information.

Let $\mathbf{X}_{t}$ denote an $N \times 1$ vector of economic time series and $\mathbf{Y}_{t}$ a vector of $M \times 1$ observable macroeconomic variables which are a subset of $\mathbf{X}_{t}$. In this context, most of the information contained in $\mathbf{X}_{t}$ is captured by $\mathbf{F}_{t}$, a $k \times 1$ vector of unobserved factors. The factors are interpreted as an addition to the observed variables, as common forces driving the dynamics of the economy. The relation between the "informational" time series $\mathbf{X}_{t}$, the observed variables $\mathbf{Y}_{t}$ and the factors $\mathbf{F}_{t}$ is represented by the following dynamic factor model:

\footnotetext{
${ }^{1}$ The basic principle behind the "Minnesota" prior is that all equations are centered around a random walk with drift. This idea has been modified by Kadiyala and Karlsson (1997) and Sims and Zha (1998). In Ingram and Whiteman (1994), a real business cycle model is used to generate a prior for a reduced form VAR, as a development of the "Minnesota" priors procedure. Also, a prior is placed on the parameters of a simple linearized DSGE, which is then compared with a Bayesian VAR in a forecasting exercise. Smets and Wouters (2003) extend this to medium scale New Keynesian models used in policy analysis. This approach has the advantage of providing information about which behavioural mechanisms produce forecast error or policy scenarios. However, it seems that it often fails to empirically fit compared to models with no behavioural structure. In Del Negro and Schorfheide (2004) and Del Negro, Schorfheide, Smets and Wouters (2007), a DSGE prior is also developed for a VAR.
} 


$$
\mathbf{X}_{t}=\mathbf{\Lambda}^{f} \mathbf{F}+\mathbf{\Lambda}^{y} \mathbf{Y}_{t}+e_{t}
$$

where $\boldsymbol{\Lambda}^{f}$ is a $N \times k$ matrix of factor loadings, $\boldsymbol{\Lambda}^{y}$ is a $N \times M$ matrix of coefficients that bridge the observable $\mathbf{Y}_{t}$ and the macroeconomic dataset, and $e_{t}$ is the vector of $N \times 1$ error terms. These terms are mean zero, normal distributed, and uncorrelated with a small cross-correlation. In fact, the estimator allows for some cross-correlation in $e_{t}$ that must vanish as $N$ goes to infinity. This representation nests also models where $\mathbf{X}_{t}$ depends on lagged values of the factors (Stock and Watson, 2002).

\subsubsection{Identification of the factors}

For the estimation of the FAVAR model equation (5), we follow the two-step principal components approach proposed by Bernanke et al. (2005). In the first step factors are obtained from the observation equation by imposing the orthogonality restriction $\mathbf{F}^{\prime} \mathbf{F} / T=\mathbf{I}$. This implies that $\hat{\mathbf{F}}=\sqrt{T} \hat{\mathbf{G}}$, where $\hat{\mathbf{G}}$ are the eigenvectors corresponding to the $K$ largest eigenvalues of $\mathbf{X X} \mathbf{X}^{\prime}$, sorted in descending order. Stock and Watson (2002) showed that the factors can be consistently estimated by the first $r$ principal components of $\mathbf{X}$, even in the presence of moderate changes in the loading matrix $\boldsymbol{\Lambda}$. For this result to hold it is important that the estimated number of factors, $k$, is larger or equal than the true number $r$. Bai and $\mathrm{Ng}$ (2000) proposed a set of selection criteria to choose $k$ that are generalizations of the BIC and AIC criteria. In the second step, we estimate the FAVAR equation replacing $\mathbf{F}_{t}$ by $\hat{\mathbf{F}}_{t}$. Following Bernanke et al. (2005), $\mathbf{Y}_{t}$ is removed from the space covered by the principal components. In a recent paper, Boivin et al. (2009) impose the constraint that $\mathbf{Y}_{t}$ is one of the common components in the first step, guaranteeing that the estimated latent factors $\hat{\mathbf{F}}_{t}$ recover the common dynamics which are not captured by $\mathbf{Y}_{t}$. The authors, comparing the two methodologies, concluded that the results are similar. As in Bernanke et al. (2005) we partition the matrix $\mathbf{X}_{t}$ in two categories of information variables: slow-moving and fast-moving. Slow-moving variables (e.g., real variables such as wages or spending) do not respond contemporaneously to unanticipated changes in monetary policy, while fast-moving (e.g., interest rates) respond contemporaneously to monetary shocks. We proceed to extracting two factors from slow variables and one factor from fast variables and we call them respectively "slow factors" and "fast factor". As suggested by Bai and Ng (2000) we use information criteria to determine the number of factors but, as they are not so decisive, we limit the number of factors to three (two slows and one fast) to strike a balance between the variance of the original series explained by the principal components and the difference in the parameterization of the VAR and the FAVAR. It is also worth noting that the factors are not uniquely identified, but this is not a problem in our context because we will not attempt a structural interpretation of the estimated factors. Finally, having determined the number of factors, we specify a Factor Augmented VAR by considering only one-lag of the factors according to BIC criterion. The potential identification of the macroeconomic shocks can be performed according to Bernanke et al. (2005) using the Cholesky decomposition.

\section{Time-varying parameter VAR model}

Time varying autoregression (TVP-VAR) models have been developed since the early 1980's. Primiceri (2005) used them in analyzing macroeconomic policy issues. The TVP-VAR model enables capturing a possible timevarying nature of underlying structure in the economy in a robust manner. In this paper, we propose a novel time-varying multivariate state-space estimation method for VAR models. Regarding the parameters of the TVP-VAR as state parameter variables, TVP autoregression could easily form a state space model. The state space model has been well studied by Harvey (1990) and Durbin and Koopman (2002). According to Kalman $(1960,1963)$, in a state-space representation the signal extraction is implemented through a model that links the unobserved and observed variables of the system. To estimate a state space model, several methods have been developed. Kalman filtering involves sequentially updating a linear projection on the vector of interest. The state-space representation is given by a system of two vector equations. First, the state or transition equation describes the dynamics of the state vector containing the unobserved variables we estimate, while the second equation represents the observation or measurement equation linking the state vector to the vector containing the observed variables. For the TVP-VAR models, the parameters are estimated using a multivariate specification of the standard Kalman filter (Harvey, 1990). The likelihood estimation 
requires repeating the filtering many times in order to evaluate the likelihood for each set of the time-varying parameters until we reach the maximum. This is performed with a suitable multivariate extension of the Kim and Nelson (1999) method. The calculation of the Hessian for the estimation of the variance-covariance matrix is done with the Broyden-Fletcher-Goldfarb-Shano (BFGS) optimization algorithm. Other algorithms can also be used with the same results, e.g., the DFP and the Levenberg-Marquardt. The parameters could be also estimated with the use of the Zellner g-prior and in this case the numerical evaluation of the posterior distributions is performed with Gibbs sampling (Kim and Nelson, 1999).

The TVP-VAR can be expressed as

$$
\mathbf{y}_{t}=\boldsymbol{\Phi}_{0, t}+\boldsymbol{\Phi}_{1, t} \mathbf{y}_{t-1}+\cdots+\boldsymbol{\Phi}_{p, t} \mathbf{y}_{t-p}+u_{t}
$$

in which $\boldsymbol{\Phi}_{0, t}$ is a $k \times 1$ vector of time-varying intercepts, $\boldsymbol{\Phi}_{i, t}(i=1, \ldots, p)$ are $k \times k$ matrices of time-varying coefficients and $u_{t}$ are homoscedastic or heteroscedastic reduced-form residuals with a covariance matrix $\boldsymbol{\Omega}_{t}$. This could be transformed into a multivariate state-space form. First, consider the following state-space system:

$$
\begin{gathered}
y_{t}=\mathbf{Z}_{t} \boldsymbol{\alpha}_{t}+\varepsilon_{t} \\
\boldsymbol{\alpha}_{t}=\mathbf{T}_{t} \boldsymbol{\alpha}_{t-1}+\boldsymbol{\eta}_{t}
\end{gathered}
$$

The first equation is known as the measurement or observation equation and presents that part of the system than can physically be measured, while the second is the state equation $\boldsymbol{\alpha}_{t}$ the vector of state variables. The variables in this equation may or may not be observable. In the case at hand, they are not observable but will be estimated by the Kalman filter. $\mathbf{Z}_{t}$ is a matrix of known or unknown time varying coefficients and matrix $\mathbf{T}_{t}$, the state transition matrix. Finally, $\varepsilon_{t}$ is $N\left(0, \sigma^{2}\right)$ while $\boldsymbol{\eta}_{t}$ in multivariate normal with an expected value of zero and a homoscedastic covariance matrix of $\mathbf{Q}^{2}$. The unknown parameters - called hyperparameters - are the elements of the matrices and the variances of the noise processes to be estimated. This is accomplished by maximizing the likelihood function which is presented below for one time period

$$
L_{t}=-\frac{1}{2} \sum_{t=1}^{T} \ln 2 \pi-\frac{1}{2} \sum_{t=1}^{T} \ln f_{t}-\frac{1}{2} \sum_{t=1}^{T} \frac{\eta_{t}^{2}}{f_{t}}
$$

where $\eta_{t}$ is the one-step ahead residual at time $t$ and $f_{t}$ is its variance. It is calculated recursively using the following equations:

$$
\begin{gathered}
\boldsymbol{\alpha}_{t \mid t-1}=\mathbf{T}_{t} \boldsymbol{\alpha}_{t} \\
\mathbf{P}_{t \mid t-1}=\mathbf{T}_{t} \mathbf{P}_{t} \mathbf{T}_{t}^{\prime}+\mathbf{Q} \\
\eta_{t}=y_{t}-\mathbf{Z}_{t} \boldsymbol{\alpha}_{t \mid t-1} \\
f_{t}=\mathbf{Z}_{t} \mathbf{P}_{t \mid t-1} \mathbf{Z}_{t}^{\prime}+\sigma^{2} \\
\boldsymbol{\alpha}_{t}=\boldsymbol{\alpha}_{t \mid t-1}+\mathbf{P}_{t \mid t-1} \mathbf{Z}_{t}^{\prime} \eta_{t} / f_{t} \\
\mathbf{P}_{t}=\mathbf{P}_{t \mid t-1}-\mathbf{P}_{t \mid t-1} \mathbf{Z}_{t}^{\prime} \mathbf{Z}_{t} \mathbf{P}_{t \mid t-1} / f_{t}
\end{gathered}
$$

Hence, Equations (10) to (15) that generate an estimate of the state vector and its covariance matrix $\mathbf{P}_{t}$ are known as the Kalman filter. Given starting values we get an estimate of the unknown regression coefficients. Then using this information in the likelihood function, one may then estimate the hyperparameters of the model. Once these estimates have been obtained, we have an estimate of the state vector, the recursive

\footnotetext{
${ }^{2}$ One basic assumption here is that the variance of the error term is constant. This assumption will be relaxed to allow for heteroscedasticity in future applications.
} 
residuals and their variance, and we can also generate an estimate of the updated residual vector $e_{t}=$ $y_{t}-\mathbf{Z}_{t} \boldsymbol{\alpha}_{t}$.

The framework for a multivariate version of the Kalman filter is provided by Harvey (1990) and it is based on a time series analogue of the seemingly unrelated regression equation (SURE) model introduced into econometrics by Zellner (1963). Harvey (1990) refers to it as a system of seemingly unrelated time series equations (SUTSE) model. The simplest SUTSE model is the multivariate random walk plus noise process:

$$
\begin{gathered}
\mathbf{y}_{t}=\boldsymbol{\alpha}_{t}+\varepsilon_{t}, \quad t=1, \ldots, T \\
\boldsymbol{\alpha}_{t}=\boldsymbol{\alpha}_{t-1}+\boldsymbol{\eta}_{t}
\end{gathered}
$$

where $\boldsymbol{\alpha}_{t}$ is an $N \times 1$ vector of local level components and $\boldsymbol{\varepsilon}_{t}$, and $\boldsymbol{\eta}_{t}$ are vectors of multivariate white noise with mean zero and covariance matrices $\boldsymbol{\Sigma}_{\varepsilon}$ and $\boldsymbol{\Sigma}_{\eta}$ respectively. As in the univariate model, $\boldsymbol{\varepsilon}_{t}$ and $\boldsymbol{\eta}_{t}$ are assumed to be uncorrelated with each other in all time periods. The variables are linked via the off-diagonal elements $\boldsymbol{\Sigma}_{\varepsilon}$ and $\boldsymbol{\Sigma}_{\eta}$. An important property of the SUTSE system is that its form remains unaltered when it is subject to contemporaneous aggregation. A linear time-invariant univariate structural model can be written in the SUTSE state space form for $N$ variables

$$
\begin{gathered}
\mathbf{y}_{t}=\left(\mathbf{z}^{\prime} \otimes \mathbf{I}_{N}\right) \boldsymbol{\alpha}_{t}+\varepsilon_{t} \\
\boldsymbol{\alpha}_{t}=\left(\mathbf{T} \otimes \mathbf{I}_{N}\right) \boldsymbol{\alpha}_{t-1}+\left(\mathbf{R} \otimes \mathbf{I}_{N}\right) \boldsymbol{\eta}_{t}
\end{gathered}
$$

with $\operatorname{Var}\left(\varepsilon_{t}\right)=\boldsymbol{\Sigma}_{\varepsilon}$ and $\operatorname{Var}\left(\boldsymbol{\eta}_{t}\right)$ a block diagonal matrix with the blocks being $\boldsymbol{\Sigma}_{k}, k=1, \ldots, g$. For example, in the three-variate case, the variance of the error component in the state equation is

$$
\operatorname{Var}\left(\boldsymbol{\eta}_{t}\right)=\left[\begin{array}{ccc}
\boldsymbol{\Sigma}_{\eta} & 0 & 0 \\
0 & \boldsymbol{\Sigma}_{\zeta} & 0 \\
0 & 0 & \boldsymbol{\Sigma}_{\omega}
\end{array}\right]
$$

A more general formulation of the SUTSE model does not constrain $\operatorname{Var}\left(\boldsymbol{\eta}_{t}\right)$ to be diagonal and hence $\operatorname{Var}\left(\boldsymbol{\eta}_{t}\right)$ need not be block diagonal. Indeed the SUTSE formulation can be generalized further to allow quantities such as $\mathbf{z}, \boldsymbol{\Sigma}_{\varepsilon}, \mathbf{T}, \mathbf{R}$ and $\operatorname{Var}\left(\boldsymbol{\eta}_{t}\right)$ to change deterministically over time. As shown in Harvey (1986), the time-domain treatment still goes through. The Kalman filter may be applied to (18) and (19), the number of sets of observations needed to form an estimator of $\boldsymbol{\alpha}_{t}$, with finite MSE matrix being the same as in the univariate case. The conditions for the filter to converge to a steady state are an obvious generalization of the conditions in the univariate case. Given normality of the disturbances, the log-likelihood function is of the prediction error decomposition form. The decoupling of the Kalman filter is related to the result which arises in a SURE system where OLS applied to each equation in turn is fully efficient if each equation contains the same regressors. Hence, all the information needed for estimation, prediction and smoothing can be obtained by applying the same univariate filter to each series in turn. Consider the multivariate random walk plus noise model. If the signal-to-noise ratio is $q$ (i.e., $\boldsymbol{\Sigma}_{\eta} / \boldsymbol{\Sigma}_{\varepsilon}=q$ ), the Kalman filter for this model is

$$
\boldsymbol{\alpha}_{t+1 \mid t}=\boldsymbol{\alpha}_{t \mid t-1}+\mathbf{K}_{t}\left(\mathbf{y}_{t}-\boldsymbol{\alpha}_{t \mid t-1}\right), t=2, \ldots, T
$$

and

$$
\mathbf{P}_{t+1 \mid t}=\mathbf{P}_{t \mid t-1}-\mathbf{P}_{t \mid t-1} \mathbf{F}_{t}^{-1} \mathbf{P}_{t \mid t-1}+q \boldsymbol{\Sigma}_{\varepsilon}
$$

where

$$
\mathbf{K}_{t}=\mathbf{P}_{t \mid t-1} \mathbf{F}_{t}^{-1}
$$

and

$$
\mathbf{F}_{t}=\mathbf{P}_{t \mid t-1}+\boldsymbol{\Sigma}_{\varepsilon}
$$

Let $w_{t}$ denote a positive scalar for $t=2, \ldots, T$ and suppose that $\mathbf{P}_{t \mid t-1}$, the MSE matrix of the $N \times 1$ vector $\boldsymbol{\alpha}_{t \mid t-1}$, is proportional to $\boldsymbol{\Sigma}_{\varepsilon}$, i.e. $\mathbf{P}_{t \mid t-1}=w_{t} \boldsymbol{\Sigma}_{\varepsilon}$. It then follows from (22) that $\mathbf{P}_{t+1 \mid t}$ is of the same form, 
that is, $\mathbf{P}_{t+1 \mid t}=w_{t+1} \boldsymbol{\Sigma}_{\varepsilon}$ with $w_{t+1}=\left(w_{t}+w_{t} q+q\right) /\left(w_{t}+1\right)$. Furthermore if $\mathbf{P}_{t \mid t-1}=w_{t} \boldsymbol{\Sigma}_{\varepsilon}$ the gain matrix in (21) is diagonal, that is

$$
\mathbf{K}_{t}=w_{t} \boldsymbol{\Sigma}_{\varepsilon}\left(w_{t} \boldsymbol{\Sigma}_{\varepsilon}+\boldsymbol{\Sigma}_{\varepsilon}\right)^{-1}=\left[w_{t} /\left(w_{t+1}\right)\right] \mathbf{I}_{N}
$$

Suppose that the above Kalman filter is started off in such a way that $\mathbf{P}_{2 \mid 1}$ is proportional to $\boldsymbol{\Sigma}_{\varepsilon}$; that is $\mathbf{P}_{2 \mid 1}=p_{2 \mid 1} \boldsymbol{\Sigma}_{\varepsilon}$, where $p_{2 \mid 1}$ is a scalar. Since $\mathbf{P}_{t \mid t-1}$ must continue to be proportional to $\boldsymbol{\Sigma}_{\varepsilon}$, it follows from (25) that the elements of $\boldsymbol{\alpha}_{t+1 \mid t}$, can be computed from the univariate recursions. It also follows that $w_{t}$, must be equal to $p_{t \mid t-1}$ for all $t=2, \ldots, T$. The starting values $\boldsymbol{\alpha}_{2 \mid 1}=\mathbf{y}_{1}$ and $\mathbf{P}_{2 \mid 1}=\boldsymbol{\Sigma}_{\eta}+\boldsymbol{\Sigma}_{\varepsilon}=(1+q) \boldsymbol{\Sigma}_{\varepsilon}$ equally correspond to the use of a diffuse prior, and the use of these starting values leads to the exact likelihood function for $\mathbf{y}_{2}, \ldots, \mathbf{y}_{T}$ in the prediction error decomposition form

$$
\log L=-\frac{(T-1) N}{2} \log 2 \pi-\frac{1}{2} \sum_{t=2}^{T} \log \left|\mathbf{F}_{t}\right|-\frac{1}{2} \sum_{t=2}^{T} \mathbf{v}_{t}^{\prime} \mathbf{F}_{t}^{-1} \mathbf{v}_{t}
$$

However, the decoupling of the Kalman filter allows the elements of $\mathbf{v}_{t}$, to be computed from the univariate recursions. Furthermore

$$
\mathbf{P}_{t \mid t-1}=p_{t \mid t-1} \boldsymbol{\Sigma}_{\varepsilon}
$$

and so

$$
\mathbf{F}_{t}=\mathbf{P}_{t \mid t-1}+\boldsymbol{\Sigma}_{\varepsilon}=f_{t} \boldsymbol{\Sigma}_{\varepsilon}, t=3, \ldots, T
$$

where $f_{t}=\left(p_{t \mid t-1}+1\right)$. Substituting from (28) into (26) gives

$$
\log L=-\frac{(T-1) N}{2} \log 2 \pi+\frac{(T-1)}{2} \log \left|\boldsymbol{\Sigma}_{\varepsilon}^{-1}\right|-\frac{N}{2} \sum_{t=2}^{T} \log f_{t}-\frac{1}{2} \sum_{t=2}^{T} \frac{1}{f_{t}} \mathbf{v}_{t}^{\prime} \boldsymbol{\Sigma}_{\varepsilon}^{-1} \mathbf{v}_{t}
$$

Differentiating (29) with respect to the distinct elements of $\boldsymbol{\Sigma}_{\varepsilon}^{-1}$ leads to the ML estimator of $\boldsymbol{\Sigma}_{\varepsilon}$ being

$$
\tilde{\boldsymbol{\Sigma}}_{\varepsilon}=(T-1)^{-1} \sum_{t=2}^{T} f_{t}^{-1} \mathbf{v}_{t} \mathbf{v}_{t}^{\prime}
$$

for any given value of $q$. The ML estimators of $q$ and $\boldsymbol{\Sigma}_{\varepsilon}$ can therefore be obtained by maximizing the concentrated likelihood function

$$
\log L_{c}=-\frac{(T-1) N}{2} \log 2 \pi-\frac{(T-1)}{2} \log \left|\tilde{\boldsymbol{\Sigma}}_{\varepsilon}\right|-\frac{N}{2} \sum_{t=2}^{T} \log f_{t}
$$

with respect to $q$. Once the parameters have been estimated, prediction and smoothing can be carried out. The predictions of future observations are obtained from the univariate recursions

$$
\operatorname{MSE}\left(\tilde{\mathbf{y}}_{T+l \mid T}\right)=f_{T+l \mid T} \boldsymbol{\Sigma}_{\varepsilon}, l=1,2, \ldots
$$

where

$$
f_{T+l \mid T}=p_{T+l \mid T}+1
$$

The decoupling of the Kalman filter can be shown in a similar way for the time-varying system

$$
\begin{gathered}
\mathbf{y}_{t}=\left(\mathbf{z}_{t}^{\prime} \otimes \mathbf{I}_{N}\right) \boldsymbol{\alpha}_{t}+\varepsilon_{t}, \operatorname{Var}\left(\varepsilon_{t}\right)=h_{t} \boldsymbol{\Sigma}_{*} \\
\boldsymbol{\alpha}_{t}=\left(\mathbf{T}_{t} \otimes \mathbf{I}_{N}\right) \boldsymbol{\alpha}_{t-1}+\left(\mathbf{R}_{t} \otimes \mathbf{I}_{N}\right) \boldsymbol{\eta}_{t}, \operatorname{Var}\left(\boldsymbol{\eta}_{t}\right)=\mathbf{Q}_{t} \otimes \boldsymbol{\Sigma}_{*}
\end{gathered}
$$

where $\mathbf{Q}_{t}=\operatorname{diag}\left(q_{1}, \ldots, q_{k}\right)$. The more general formulation does not constrain $\mathbf{Q}_{t}$ to be diagonal, although, as in the univariate model, restrictions are needed on $\mathbf{Q}_{t}$ for the model to be identifiable. All the results on estimation and prediction carry through, with $\mathbf{P}_{t+1 \mid t}=\mathbf{P}_{t+1 \mid t}^{*} \otimes \boldsymbol{\Sigma}_{*}$, where $\mathbf{P}_{t+1 \mid t}^{*}$ is the MSE matrix for the univariate model (Harvey 1986, 1990). 


\section{DSGE Modeling}

Only recently and after the seminal work of Smets and Wouters $(2003,2004)$ the DSGE models have been considered as forecasting tools in macroeconomic literature. Model validation, estimation and calibration are crucial issues in DSGE structure. The main problems are reported in Canova (1994). Calibrated DSGE models often yield fragile results, when traditional econometric methods are used for estimation (Smets and Wouters 2003; Ireland 2004). Following this idea of combining the DSGE model information and the VAR representation, among other models that have been proposed in the literature, in this study we use the DSGE-VAR and DSGE-FAVAR hybrid models.

\subsection{Simple DSGE model}

Simple DSGE models with forward-looking features are usually referred to as a benchmarks in the literature. In a DSGE setup the economy is made up of four components. The first component is the representative household with habit persistent preferences. This household maximizes an additively separable utility function which is separable into consumption, real money balances and hours worked over an infinite lifetime. The household gains utility from consumption relative to the level of technology, real balances of money, and disutility from hours worked. The household earns interest from holding government bonds and earns real profits from the firms. Moreover, the representative household pays lump-sum taxes to the government. The second component is a perfectly competitive, representative final goods producer which is assumed to use a continuum of intermediate goods as inputs, and the prices for these inputs are given. The producers of these intermediate goods are monopolistic firms which use labour as the only input. The production technology is the same for all the monopolistic firms. Nominal rigidities are introduced in terms of price adjustment costs for the monopolistic firms. Each firm maximizes its profits over an infinite lifetime by choosing its labour input and its price. The third component is the government which spends in each period a fraction of the total output, which fluctuates exogenously. The government issues bonds and levies lump-sum taxes, which are the main part of its budget constraint. The last component is the monetary authority, which follows a Taylor rule regarding the inflation target and the output gap. There are three economic shocks: an exogenous monetary policy shock (in the monetary policy rule), and two autoregressive processes, AR(1), which model government spending and technology shocks. To solve the model, optimality conditions are derived for the maximization problems. After linearization around the steady-state, the economy is described by the following system of equations

$$
\begin{gathered}
\tilde{x}_{t}=E_{t}\left[\tilde{x}_{t+1}\right]-\frac{1}{\tau}\left(\tilde{R}_{t}-E_{t}\left[\tilde{\pi}_{t+1}\right]\right)+\left(1-\rho_{g}\right) \tilde{g}_{t}+\rho_{Z} \frac{1}{\tau} \tilde{z}_{t} \\
\tilde{\pi}_{t}=\beta E_{t}\left[\tilde{\pi}_{t+1}\right]+\kappa\left[\tilde{x}_{t}-\tilde{g}_{t}\right] \\
\tilde{R}_{t}=\rho_{R} \tilde{R}_{t-1}+\left(1-\rho_{R}\right)\left(\psi_{1} \tilde{\pi}_{t}+\psi_{2} \tilde{x}_{t}\right)+\epsilon_{R, t} \\
\tilde{g}_{t}=\rho_{g} \tilde{g}_{t-1}+\epsilon_{g, t} \\
\tilde{z}_{t}=\rho_{z} \tilde{z}_{t-1}+\epsilon_{z, t},
\end{gathered}
$$

where $x$ is the detrended output (divided by the non-stationary technology process), $\pi$ is the gross inflation rate, and $R$ is the gross nominal interest rate. The tilde denotes percentage deviations from a steady state or, in the case of output, from a trend path (King, 2000; Woodford, 2003). The model can be solved by applying

the algorithm proposed by Sims (2002). Define the vector of variables $\tilde{Z}_{t}=\left(\tilde{x}_{t}, \tilde{\pi}_{t}, \tilde{R}_{t}, \tilde{g}_{t}, \tilde{z}_{t}, E_{t} \tilde{x}_{t+1}, E_{t} \tilde{\pi}_{t+1}\right)$ and the vector of shocks as $\epsilon_{t}=\left(\epsilon_{R, t}, \epsilon_{g, t}, \epsilon_{z, t}\right)$. Therefore the previous set of equations, (36) - (40), can be recasted into a set of matrices $\left(\Gamma_{0}, \Gamma_{1}, C, \Psi, \Pi\right)$ accordingly to the definition of the vectors $\tilde{Z}_{t}$ and $\epsilon_{t}$

$$
\Gamma_{0} \tilde{Z}_{t}=C+\Gamma_{1} \tilde{Z}_{t-1}+\Psi \epsilon_{t}+\Pi \eta_{t}
$$

where $\eta_{t+1}$, such that $E_{t} \eta_{t+1} \equiv E_{t}\left(y_{t+1}-E_{t} y_{t+1}\right)=0$, is the expectations error. 
As a solution to (41), we obtain the following transition equation as a policy function

$$
\tilde{Z}_{t}=T(\theta) \tilde{Z}_{t-1}+R(\theta) \epsilon_{t}
$$

and in order to provide the mapping between the observable data and those computed as deviations from the steady state of the model we set the following measurement equations as in Del Negro and Schorfheide (2004):

$$
\begin{gathered}
\Delta \ln x_{t}=\ln \gamma+\Delta \tilde{x}_{t}+\tilde{z}_{t} \\
\Delta \ln P_{t}=\ln \pi^{*}+\tilde{\pi}_{t} \\
\ln R_{t}^{a}=4\left[\left(\ln r^{*}+\ln \pi^{*}\right)+\tilde{R}_{t}\right]
\end{gathered}
$$

which can be also casted into matrices as

$$
Y_{t}=\Lambda_{0}(\theta)+\Lambda_{1}(\theta) \tilde{Z}_{t}+v_{t}
$$

where $Y_{t}=\left(\Delta \ln x_{t}, \Delta \ln P_{t}, \ln R_{t}\right)^{\prime}, v_{t}=0$ and $\Lambda_{0}$ and $\Lambda_{1}$ are defined accordingly. For completeness, we write the matrices $T, R, \Lambda_{0}$ and $\Lambda_{1}$ as a function of the structural parameters in the model, $\theta=$ $\left(\ln \gamma, \ln \pi^{*}, \ln r^{*}, \kappa, \tau, \psi_{1}, \psi_{2}, \rho_{R}, \rho_{g}, \rho_{Z}, \sigma_{R}, \sigma_{g}, \sigma_{Z}\right)^{\prime}$. Such a formulation derives from the rational expectations solution. The evolution of the variables of interest, $Y_{t}$, is therefore determined by (42) and (44) which impose a set of restrictions across the parameters on the moving average (MA) representation. Given that the MA representation can be very closely approximated by a finite order VAR representation, Del Negro and Schorfheide (2004) propose to evaluate the DSGE model by assessing the validity of the restrictions imposed by such a model with respect to an unrestricted VAR representation. The choice of the variables to be included in the VAR is however completely driven by those entering in the DSGE model regardless of the statistical goodness of the unrestricted VAR.

\subsection{DSGE-VAR}

Del Negro-Schorfheide's (2004) approach is to use the DSGE model to build prior distributions for the VAR. Basically, the estimation initializes with an unrestricted VAR of order $\mathrm{p}$

$$
\mathbf{Y}_{t}=\boldsymbol{\Phi}_{0}+\boldsymbol{\Phi}_{1} \mathbf{Y}_{t-1}+\ldots+\boldsymbol{\Phi}_{p} \mathbf{Y}_{t-p}+\mathbf{u}_{t}
$$

In compact format:

$$
\mathbf{Y}=\mathbf{X} \Phi+\mathbf{U}
$$

$\mathbf{Y}$ is a $(T \times n)$ matrix with rows $Y_{t}^{\prime}, \mathbf{X}$ is a $(T \times k)$ matrix $(k=1+n p, p=$ number of lags $)$ with rows $X_{t}^{\prime}=\left[1, Y_{t-1}^{\prime}, \ldots, Y_{t-p}^{\prime}\right], \mathbf{U}$ is a $(T \times n)$ matrix with rows $u_{t}^{\prime}$ and $\Phi$ is a $(k \times n)=\left[\Phi_{0}, \Phi_{1, \ldots}, \Phi_{p}\right]^{\prime}$. The one-stepahead forecast errors $u_{t}$ have a multivariate normal distribution $N\left(0, \Sigma_{u}\right)$ conditional on past observations of $Y$. The log-likelihood function of the data is a function of $\Phi$ and $\Sigma_{u}$

$$
L\left(\mathbf{Y} \mid \Phi, \Sigma_{u}\right) \propto\left|\Sigma_{u}\right|^{-\frac{T}{2}} \exp \left\{-\frac{1}{2} \operatorname{tr}\left[\Sigma_{u}^{-1}\left(\mathbf{Y}^{\prime} \mathbf{Y}-\mathbf{\Phi}^{\prime} \mathbf{X}^{\prime} \mathbf{Y}-\mathbf{Y}^{\prime} \mathbf{X} \mathbf{\Phi}+\mathbf{\Phi}^{\prime} \mathbf{X}^{\prime} \mathbf{X} \boldsymbol{\Phi}\right)\right]\right\}
$$

The prior distribution for the VAR parameters proposed by Del Negro and Schorfheide (2004) is based on the statistical representation of the DSGE model given by a VAR approximation. Let $\Gamma_{x x}^{*}, \Gamma_{y y}^{*}, \Gamma_{x y}^{*}$ and $\Gamma_{y x}^{*}$ be the theoretical second-order moments of the variables $Y$ and $X$ implied by the DSGE model, where

$$
\begin{gathered}
\Phi^{*}(\theta)=\Gamma_{x x}^{*-1}(\theta) \Gamma_{x y}^{*}(\theta) \\
\Sigma^{*}(\theta)=\Gamma_{y y}^{*}(\theta)-\Gamma_{y x}^{*}(\theta) \Gamma_{x x}^{*-1}(\theta) \Gamma_{x y}^{*}(\theta)
\end{gathered}
$$

The moments are the dummy observation priors used in the mixture model. These vectors can be interpreted as the probability limits of the coefficients in a VAR estimated on the artificial observations generated by the DSGE model. Conditional on the vector of structural parameters in the DSGE model $\theta$, the prior distributions for the VAR parameters $p\left(\Phi, \Sigma_{u} \mid \theta\right)$ are of the Inverted-Wishart (IW) and Normal forms

$$
\begin{gathered}
\Sigma_{u} \mid \theta \sim I W\left(\left(\lambda T \Sigma_{u}^{*}(\theta), \lambda T-k, n\right)\right. \\
\boldsymbol{\Phi} \mid \Sigma_{u}, \theta \sim N\left(\boldsymbol{\Phi}^{*}(\theta), \Sigma_{u} \otimes\left(\lambda T \Gamma_{X X}(\theta)\right)^{-1}\right)
\end{gathered}
$$


where the parameter $\lambda$ controls the degree of model misspecification with respect to the VAR: for small values of $\lambda$ the discrepancy between the VAR and the DSGE-VAR is large and a sizeable distance is generated between the unrestricted VAR and DSGE estimators. Large values of $\lambda$ correspond to small model misspecification and for $\lambda=\infty$ beliefs about DSGE misspecification degenerate to a point mass at zero. Bayesian estimation could be interpreted as estimation based on a sample in which data are augmented by a hypothetical sample in which observations are generated by the DSGE model, the so-called dummy prior observations (Theil and Goldberg, 1961; Ingram and Whiteman, 1994). Within this framework $\lambda$ determines the length of the hypothetical sample. The posterior distributions of the VAR parameters are also of the Inverted-Wishart and Normal forms. Given the prior distribution, posterior distributions are derived by the Bayes theorem

$$
\begin{gathered}
\Sigma_{u} \mid \theta, \mathbf{Y} \sim I W\left((\lambda+1) T \hat{\Sigma}_{u, b}(\theta),(\lambda+1) T-k, n\right) \\
\mathbf{\Phi} \mid \Sigma_{u}, \theta, \mathbf{Y} \sim N\left(\hat{\mathbf{\Phi}}_{b}(\theta), \Sigma_{u} \otimes\left[\lambda T \Gamma_{X X}(\theta)+\mathbf{X}^{\prime} \mathbf{X}\right]^{-1}\right) \\
\hat{\mathbf{\Phi}}_{b}(\theta)=\left(\lambda T \Gamma_{X X}(\theta)+\mathbf{X}^{\prime} \mathbf{X}\right)^{-1}\left(\lambda T \Gamma_{X Y}(\theta)+\mathbf{X}^{\prime} \mathbf{Y}\right) \\
\hat{\Sigma}_{u, b}(\theta)=\frac{1}{(\lambda+1) T}\left[\left(\lambda T \Gamma_{Y Y}(\theta)+\mathbf{Y}^{\prime} \mathbf{Y}\right)-\left(\lambda T \Gamma_{X Y}(\theta)+\mathbf{X}^{\prime} \mathbf{Y}\right) \hat{\mathbf{\Phi}}_{b}(\theta)\right]
\end{gathered}
$$

where the matrices $\hat{\boldsymbol{\Phi}}_{b}(\theta)$ and $\hat{\Sigma}_{u, b}(\theta)$ have the interpretation of maximum likelihood estimates of the VAR parameters based on the combined sample of actual observations and artificial observations generated by the DSGE. Equations (50) and (51) show that the smaller $\lambda$ is, the closer the estimates are to the OLS estimates of an unrestricted VAR. Instead, the higher $\lambda$ is, the closer the VAR estimates will be tilted towards the parameters in the VAR approximation of the DSGE model $\left(\hat{\boldsymbol{\Phi}}_{b}(\theta)\right.$ and $\left.\hat{\Sigma}_{u, b}(\theta)\right)$. In order to obtain a non-degenerate prior density (49), which is a necessary condition for the existence of a well-defined Inverse-Wishart distribution and for computing meaningful marginal likelihoods, $\lambda$ has to be greater than $\lambda_{M I N}$

$$
\begin{aligned}
\lambda_{M I N} & \geq \frac{n+k}{T} ; k=1+p \times n \\
p & =\text { lags } \\
n & =\text { endogenous variables. }
\end{aligned}
$$

Hence, the optimal lambda must be greater than or equal to the minimum lambda $\left(\hat{\lambda} \geq \lambda_{M I N}\right)$.

Essentially, the DSGE-VAR tool allows the econometrician to draw posterior inferences about the DSGE model parameters $\theta$. Del Negro and Schorfheide (2004) explain that the posterior estimate of $\theta$ has the interpretation of a minimum-distance estimator, where the discrepancy between the OLS estimates of the unrestricted VAR parameters and the VAR representation of the DSGE model is a sort of distance function. The estimated posterior of parameter vector $\theta$ depends on the hyperparameter $\lambda$. When $\lambda \rightarrow 0$, in the posterior the parameters are not informative, so the DSGE model is of no use in explaining the data. Unfortunately, the posteriors (51) and (50) do not have a closed form and we need a numerical method to solve the problem. The posterior simulator used by Del Negro and Schorfheide (2004) is the Markov Chain Monte Carlo Method and the algorithm used is the Metropolis-Hastings acceptance method. This procedure generates a Markov Chain from the posterior distribution of $\theta$ and this Markov Chain is used for Monte Carlo simulations. The optimal $\lambda$ is given by maximizing the $\log$ of the marginal data density

$$
\hat{\lambda}=\underset{\lambda \geqslant \lambda_{M I N}}{\arg \max } \ln p(\mathbf{Y} \mid \lambda)
$$

According to the optimal lambda $(\hat{\lambda})$, a corresponding optimal mixture model is chosen. This hybrid model is called DSGE-VAR $(\hat{\lambda})$ and $\hat{\lambda}$ is the weight of the priors. It can also be interpreted as the restriction of the theoretical model on the actual data. 


\subsection{DSGE-FAVAR}

According to Bernanke et al. (2005), a FAVAR benchmark for the evaluation of a DSGE model will include a vector of observable variables and a small vector of unobserved factors extracted from a large data-set of macroeconomic time series, that capture additional economic information relevant to model the dynamics of the observables. In this study we implement the DSGE-FAVAR model of Consolo et al. (2009). The statistical representation has the following specification:

$$
\begin{aligned}
\left(\begin{array}{l}
\mathbf{Y}_{t} \\
\mathbf{F}_{t}
\end{array}\right) & =\left[\begin{array}{ll}
\boldsymbol{\Phi}_{11}(L) & \boldsymbol{\Phi}_{12}(L) \\
\mathbf{\Phi}_{21}(L) & \boldsymbol{\Phi}_{22}(L)
\end{array}\right]\left(\begin{array}{l}
\mathbf{Y}_{t-1} \\
\mathbf{F}_{t-1}
\end{array}\right)+\left(\begin{array}{c}
\mathbf{u}_{t}^{Y} \\
\mathbf{u}_{t}^{F}
\end{array}\right) \\
\mathbf{Y}_{t} & =\left(\Delta \ln x_{t}, \Delta \ln P_{t}, \ln R_{t}\right) \\
\mathbf{F}_{t} & =\left(F_{1 t}^{s}, F_{2 t}^{s}, F_{3 t}^{f}\right)
\end{aligned}
$$

where $\mathbf{Y}_{t}$ are the observable variables included in the simple DSGE model and $\mathbf{F}_{t}$ is a small vector of unobserved factors relevant to modelling the dynamics of $\mathbf{Y}_{t}\left(F_{1 t}^{s}, F_{2 t}^{s}\right.$ are the two slow factors and $F_{3 t}^{f}$ is the fast factor). The system reduces to the standard VAR when $\Phi_{12}(L)=0$. Importantly, and differently from Boivin and Giannoni (2006), this FAVAR is not interpreted as the reduced form of a DSGE model at hand. In fact, in this case the restrictions implied by the DSGE model on a general FAVAR are very difficult to trace and model evaluation becomes even more difficult to implement. A very tightly parameterized theory model can have a very highly parameterized reduced form if one is prepared to accept that the relevant theoretical concepts in the model are a combination of many macroeconomic and financial variables. The DSGE-FAVAR is implemented in the same way as the DSGE-VAR.

\section{Empirical results}

The dataset consists of a panel of 46 quarterly macroeconomic time series for the Euro Area from the AWM database (Fagan et al., 2001), spanning the period from 1970:1 to 2010:4. The AWM database includes publicly available data produced by Eurostat and reported in the ECB Monthly Bulletin with a supplement for aggregated country data. Data prior to 1996 are drawn from the last version of the AWM database, while the current version extends the series to 2010:4 with a fixed composition of the Euro area with 17 members. The complete dataset is used to extract factors for FAVAR and DSGE-FAVAR models. The forecasting exercise conducted in this paper uses three series: the real GDP (symbolized as YER in AWM database), the seasonally adjusted Harmonized Consumer Price Index (symbolized as HICPSA) - both taken in first difference logarithmic transformation - and the nominal Short-term Interest Rate (symbolized as STN). In this paper we use the AWM symbols for each variable, respectively. The panel data has been transformed to induce stationarity. The series are considered in level, logarithms, first or second differences according to series characteristics ${ }^{3}$. Following Bernanke et al. (2005) we partition the data in two categories of information variables: slow and fast. Slow-moving variables (e.g., wages or spending) do not respond contemporaneously to unanticipated changes in monetary policy, while fast-moving variables (e.g., asset prices and interest rates) do respond contemporaneously to monetary shocks.

\footnotetext{
${ }^{3}$ The Appendix contains a detailed description of all series and their corresponding transformations.
} 
Table 1: Prior Distributions for the DSGE model parameters

\begin{tabular}{lllccc}
\hline \hline Name & Range & Density & Starting value & Mean & Standard deviation \\
\hline $\ln \gamma$ & $\mathbb{R}$ & Normal & 0.500 & 0.500 & 0.250 \\
$\ln \pi^{*}$ & $\mathbb{R}$ & Normal & 1.000 & 1.000 & 0.500 \\
$\ln r^{*}$ & $\mathbb{R}^{+}$ & Gamma & 0.500 & 0.500 & 0.250 \\
$\kappa$ & $\mathbb{R}^{+}$ & Gamma & 0.040 & 0.030 & 0.150 \\
$\tau$ & $\mathbb{R}^{+}$ & Gamma & 3.000 & 3.000 & 0.500 \\
$\psi_{1}$ & $\mathbb{R}^{+}$ & Gamma & 1.500 & 1.500 & 0.250 \\
$\psi_{2}$ & $\mathbb{R}^{+}$ & Gamma & 0.300 & 0.125 & 0.100 \\
$\rho_{R}$ & {$[0,1)$} & Beta & 0.400 & 0.500 & 0.200 \\
$\rho_{G}$ & {$[0,1)$} & Beta & 0.800 & 0.800 & 0.100 \\
$\rho_{Z}$ & {$[0,1)$} & Beta & 0.200 & 0.200 & 0.100 \\
$\sigma_{R}$ & $\mathbb{R}^{+}$ & Inv.Gamma & 0.100 & 0.100 & 0.139 \\
$\sigma_{G}$ & $\mathbb{R}^{+}$ & Inv.Gamma & 0.300 & 0.350 & 0.323 \\
$\sigma_{Z}$ & $\mathbb{R}^{+}$ & Inv.Gamma & 0.400 & 0.875 & 0.430 \\
\hline \hline
\end{tabular}

Note: The model parameters $\ln \gamma, \ln \pi^{*}, \ln r^{*}, \sigma_{R}, \sigma_{g}$, and $\sigma_{z}$ are scaled by 100 to convert them into percentages. The Inverse Gamma priors are of the form $p(\sigma \mid \nu, s) \propto \sigma^{-\nu-1} e^{-\nu s^{2} / 2 \sigma^{2}}$, where $\mathrm{v}=4$ and s equals $0.2,0.5$, and 0.7 , respectively. Approximately $1.5 \%$ of the prior mass lies in the indeterminacy region of the parameter space. The prior is truncated to restrict it to the determinacy region of the DSGE model .

We compare the out-of-sample forecasting performance of VAR models including BVAR and FAVAR, of the DSGE class including DSGE-VAR, DSGE-FAVAR and of the multivariate state space TVP-VAR, in terms of the Mean Squared Forecast Error (MSFE) and Mean Absolute Forecast Error (MAFE) for different lag specifications (one to four). The YER, HICPSA and STN forecasts are estimated for the out-of-sample testing period 2006:1-2010:4, while the in-sample spans from 1970:1 to 2005:4. As in Marcellino (2003, 2004) and Brüggemann et al. (2008), the forecasting investigation for quarterly Euro area data is performed over the one-, two-, four- and eight-quarter-ahead horizon with a rolling estimation sample. In particular, the models are re-estimated each quarter over the forecast horizon to update the estimate of the coefficients, before producing the quarter-ahead forecasts. Finally, in order to evaluate the models' forecast accuracy, we use the cross-model test statistic of Diebold and Mariano (1995).

The prior distribution for the DSGE model parameters $(\theta)$, which are similar to the priors used by Del Negro and Schorfheide (2004), are illustrated in Table 1. The forecasted values are produced implementing the $\operatorname{DSGE-VAR}(\hat{\lambda})$, where the $\hat{\lambda}$ is chosen by the numerical procedure for each estimation. In the forecasting evaluation, the DSGE-VAR is estimated with a different number of lags on the sample spanning from 1970:2 to 2005:4. The parameter $\lambda$ is chosen from a grid which is unbounded from above. In our empirical exercise, the $\log$ of the marginal data density is computed over a discrete interval, $\ln p(Y \mid \lambda, M)$. The minimum value, $\lambda_{\min }=\frac{n+k}{T}$, is model dependent and is related to the existence of a well-defined Inverse-Wishart distribution. For completeness, it is worth mentioning that $\lambda=0$ refers to the VAR model with no prior and it is not possible to compute the marginal likelihood in this particular case. Therefore, we can show the log of marginal data density for any value of $\lambda$ larger than $\lambda_{\min }$. Thus, $\lambda_{\text {min }}$ depends on the degrees of freedom in the VAR.

Table 2 shows the main results related to the DSGE-VAR implemented using a different number of lags (from one up to four) across the different steps ahead (1,2,4 and 8) implemented in the forecasting exercise. Each minimum $\lambda\left(\lambda_{M I N}\right)$ is given by the features of the model (number of observations, number of endogenous variables, number of lags) and the optimal lambda $(\hat{\lambda})$ is calculated using the Markov Chain Monte Carlo with Metropolis Hastings acceptance method (100,000 replications) $)^{4}$. The $\ln p(Y \mid M)$ is the log marginal data density for the DSGE model specifications computed based on Geweke' s (1999) modified harmonic mean estimator. The Bayes factor (ratio of posterior odds to prior odds) (Schorfheide 2010) helps in understanding the improvement of the log marginal data density of a specific model compared to a benchmark model, which for the MCMC exercise is the DSGE-VAR (4) (i.e., the Akaike and Schwartz information criteria select 4

\footnotetext{
${ }^{4}$ The lambda grid is composed of $\{0,0.05,0.08,0.10,0.12,0.15,0.20,0.25,0.30,0.35,0.40,0.45,0.50,0.55,0.60,0.65,0.70$, $0.75,0.80,0.85,0.90,1,5,10\}$.
} 
Table 2: Optimal lambda for the DSGE-VAR calculated with Markov Chain Monte Carlo and Metropolis Hastings method

\begin{tabular}{|c|c|c|c|c|c|c|}
\hline & $\lambda_{M I N}$ & $\hat{\lambda}$ & $\hat{\lambda}-\lambda_{M I N}$ & $\frac{\hat{\lambda}-\lambda_{M I N}}{\lambda_{M L N}}$ & $\ln p(Y \mid \hat{\lambda}, M)$ & Bayes Factor \\
\hline \multicolumn{7}{|l|}{ One-step ahead } \\
\hline DSGE-VAR(1) & 0.05 & 0.15 & 0.10 & 2 & -360.601 & $\exp [28.731]$ \\
\hline $\operatorname{DSGE}-\operatorname{VAR}(2)$ & 0.08 & 0.20 & 0.12 & 1.5 & -349.587 & $\exp [17.717]$ \\
\hline $\operatorname{DSGE-VAR}(3)$ & 0.10 & 0.20 & 0.10 & 1 & -350.672 & $\exp [18.802]$ \\
\hline DSGE-VAR(4) & 0.12 & 0.35 & 0.23 & 1.917 & -331.870 & 1 \\
\hline \multicolumn{7}{|l|}{ Two-steps ahead } \\
\hline DSGE-VAR(1) & 0.05 & 0.20 & 0.15 & 3 & -367.299 & $\exp [32.858]$ \\
\hline $\operatorname{DSGE-VAR}(2)$ & 0.08 & 0.30 & 0.22 & 2.75 & -352.267 & $\exp [17.826]$ \\
\hline DSGE-VAR(3) & 0.10 & 0.30 & 0.20 & 2 & -351.020 & $\exp [16.579]$ \\
\hline DSGE-VAR(4) & 0.12 & 0.35 & 0.23 & 1.917 & -334.441 & 1 \\
\hline \multicolumn{7}{|l|}{ Four-steps ahead } \\
\hline DSGE-VAR(1) & 0.05 & 0.20 & 0.15 & 3 & -375.727 & $\exp [37.781]$ \\
\hline $\operatorname{DSGE}-\operatorname{VAR}(2)$ & 0.08 & 0.20 & 0.12 & 1.5 & -358.486 & $\exp [20.540]$ \\
\hline DSGE-VAR(3) & 0.10 & 0.35 & 0.25 & 2.5 & -354.832 & $\exp [16.886]$ \\
\hline DSGE-VAR(4) & 0.12 & 0.35 & 0.23 & 1.917 & -337.946 & 1 \\
\hline \multicolumn{7}{|l|}{ Eight-steps ahead } \\
\hline DSGE-VAR(1) & 0.05 & 0.12 & 0.07 & 1.4 & -387.408 & $\exp [40.579]$ \\
\hline DSGE-VAR $(2)$ & 0.08 & 0.20 & 0.12 & 1.5 & -368.363 & $\exp [21.534]$ \\
\hline DSGE-VAR(3) & 0.10 & 0.30 & 0.20 & 2 & -368.226 & $\exp [21.397]$ \\
\hline DSGE-VAR(4) & 0.12 & 0.40 & 0.28 & 2.333 & -346.829 & 1 \\
\hline
\end{tabular}

lags on the data). The same exercise is reproduced for the DSGE-FAVAR. ${ }^{5}$ In this case, the lag length for factors is fixed to one based on the Schwartz criterion. The Bayes factor again selects a DSGE-FAVAR with 4 lags as depicted in Table 3 .

Tables 4, 5 and 6 report the MSFE and MAFE for all models and variables. While the number of lags indicated by the Schwartz Bayesian information criterion (SIC) for the benchmark VAR model was two i.e., a VAR(2) model, the Akaike (AIC) and the Hannan-Quinn criteria denoted a higher and varying number of lags for all VAR investigated models. Thus, an exhaustive exercise was conducted with one to four lags in each case. The results later on provide further validation of the decision to use more than one lag selection (as opposed to the empirical literature so far), in that the best performance in each model class derives from different specification most of the times. Firstly, for the YER series the simple DGSE model provides the lowest MSFE for the first two forecasting horizons (i.e., one- and two-steps ahead) while the TVP-VAR(4) and TVP-VAR(1) outperform the other models for four- and eight-quarters-ahead. In terms of the MAFE, the DGSE achieves a better score for the two- and four-period-ahead, while the DSGE-FAVAR(4) and TVPVAR(1) produce the lowest scores for one- and eight-periods-ahead, respectively. The lowest MSFEs after the DSGE and TVP-VARs come from FAVAR and DSGE-FAVAR models. The VAR and BVAR models present similar predictive performance and on average they generate the highest forecast errors, albeit BVARs slightly better for all steps-ahead. Moreover, the DSGE-VAR provides with similar MSFE and MAFE as DGSEFAVAR for any lag structure over all quarter-ahead forecasts. Regarding the HICPSA variable, the TVP-VAR models are the winners. In particular, for the one- and eight-quarter-ahead forecasts the TVP-VAR(4) clearly outperforms all other models, while for the two- and four-quarter-ahead the TVP-VAR(3) gives the lowest MSFE and MAFE. The other two TVP-VAR specifications also outrank with a few exceptions the other

\footnotetext{
${ }^{5}$ For the DSGE-FAVAR, the lambda grid is composed of $\{0,0.08,0.10,0.12,0.14,0.15,0.20,0.25,0.30,0.35,0.40,0.45,0.50$, $0.55,0.60,0.65,0.70,0.75,0.80,0.85,0.90,1,5,10\}$.
} 
Table 3: Optimal lambda for the DSGE-FAVAR calculated with Markov Chain Monte Carlo and Metropolis Hastings method

\begin{tabular}{|c|c|c|c|c|c|c|}
\hline & $\lambda_{M I N}$ & $\hat{\lambda}$ & $\hat{\lambda}-\lambda_{M I N}$ & $\frac{\hat{\lambda}-\lambda_{M I N}}{\lambda_{M L N}}$ & $\ln p(Y \mid \hat{\lambda}, M)$ & Bayes Factor \\
\hline \multicolumn{7}{|l|}{ One-step ahead } \\
\hline DSGE-FAVAR(1) & 0.08 & 0.30 & 0.22 & 2.75 & -374.647 & $\exp [29.927]$ \\
\hline DSGE-FAVAR $(2)$ & 0.10 & 0.30 & 0.20 & 2 & -364.160 & $\exp [19.440]$ \\
\hline DSGE-FAVAR(3) & 0.12 & 0.35 & 0.23 & 1.916 & -356.673 & $\exp [11.953]$ \\
\hline DSGE-FAVAR(4) & 0.14 & 0.50 & 0.36 & 2.57 & -344.720 & 1 \\
\hline \multicolumn{7}{|l|}{ Two-steps ahead } \\
\hline DSGE-FAVAR(1) & 0.08 & 0.14 & 0.06 & 0.75 & -376.244 & $\exp [33.042]$ \\
\hline DSGE-FAVAR(2) & 0.10 & 0.25 & 0.15 & 1.50 & -365.762 & $\exp [22.560]$ \\
\hline DSGE-FAVAR(3) & 0.12 & 0.40 & 0.28 & 2.33 & -359.078 & $\exp [15.876]$ \\
\hline DSGE-FAVAR(4) & 0.14 & 0.45 & 0.31 & 2.21 & -343.202 & 1 \\
\hline \multicolumn{7}{|l|}{ Four-steps ahead } \\
\hline DSGE-FAVAR(1) & 0.08 & 0.25 & 0.17 & 2.125 & -383.852 & $\exp [32.694]$ \\
\hline DSGE-FAVAR (2) & 0.10 & 0.50 & 0.40 & 4 & -373.803 & $\exp [22.645]$ \\
\hline DSGE-FAVAR(3) & 0.12 & 0.45 & 0.33 & 2.75 & -366.619 & $\exp [15.461]$ \\
\hline DSGE-FAVAR(4) & 0.14 & 0.45 & 0.31 & 2.214 & -351.158 & 1 \\
\hline \multicolumn{7}{|l|}{ Eight-steps ahead } \\
\hline DSGE-FAVAR(1) & 0.08 & 0.25 & 0.17 & 2.125 & -392.959 & $\exp [36.093]$ \\
\hline DSGE-FAVAR (2) & 0.10 & 0.25 & 0.15 & 1.5 & -382.931 & $\exp [26.065]$ \\
\hline DSGE-FAVAR(3) & 0.12 & 0.40 & 0.28 & 2.333 & -377.985 & $\exp [21.119]$ \\
\hline DSGE-FAVAR(4) & 0.14 & 0.45 & 0.31 & 2.214 & -356.866 & 1 \\
\hline
\end{tabular}

model classes. In general, the MSFE and MAFE scores are almost identical and after the TVP-VARs, the DSGE-FAVAR and the simple DGSE show the best performance. FAVAR models seem slightly better than BVARs, whilst DSGE-VARs and VARs provide with relatively good scores especially for four- and eightquarters-ahead. The results for the STN series vary when comparing MSFE and MAFE but also in terms of the outperforming model class. The MAFE scores indicate three different model classes as the best performers in each forecasting horizon, namely the DSGE-VAR(3) for one-step-ahead, the BVAR(1) for two steps, the FAVAR(1) for four and FAVAR(4) for eight-quarter-ahead forecasts. This heterogeneity in forecastability is waived when MSFE scores are examined, with the lowest observed for the simple DGSE and the FAVAR(4) model. In particular, the simple DGSE outperforms all models in case of one- and four-steps-ahead, whereas FAVAR(4) for two and eight. However, a more qualitative investigation reveals a pattern both for MSFE and MAFE scores; for one-step-ahead forecasts the DGSE-VARs and BVARs provide with relatively low errors compared to the other models, while for the two-, four- and eight-quarters-ahead FAVAR modelling shows on average the best performance. Overall, the DSGE-VAR and the BVAR models produce similar scores with the FAVAR, whereas DSGE-FAVARs, simple VARs and the state-space TVP-VARs underperform relatively to the other models. 
Table 4: Mean Square Forecast Error (MSFE) and Mean Absolute Forecast Error (MAFE) scores for the Euro area GDP (YER)

\begin{tabular}{|c|c|c|c|c|c|c|c|c|}
\hline \multirow{3}{*}{ YER } & \multicolumn{4}{|c|}{ MSFE } & \multicolumn{4}{|c|}{ MAFE } \\
\hline & \multicolumn{4}{|c|}{ Quarters ahead } & \multicolumn{4}{|c|}{ Quarters ahead } \\
\hline & 1 & 2 & 4 & 8 & 1 & 2 & 4 & 8 \\
\hline $\operatorname{VAR}(1)$ & 1.689 & 1.770 & 1.774 & 1.707 & 0.810 & 0.878 & 0.902 & 0.903 \\
\hline $\operatorname{VAR}(2)$ & 1.688 & 1.762 & 1.782 & 1.725 & 0.817 & 0.880 & 0.902 & 0.913 \\
\hline $\operatorname{VAR}(3)$ & 1.650 & 1.719 & 1.732 & 1.689 & 0.805 & 0.855 & 0.883 & 0.896 \\
\hline $\operatorname{VAR}(4)$ & 1.603 & 1.662 & 1.692 & 1.612 & 0.786 & 0.817 & 0.877 & 0.875 \\
\hline $\operatorname{BVAR}(1)$ & 1.701 & 1.696 & 1.739 & 1.673 & 0.809 & 0.847 & 0.883 & 0.885 \\
\hline $\operatorname{BVAR}(2)$ & 1.685 & 1.691 & 1.726 & 1.673 & 0.805 & 0.858 & 0.882 & 0.881 \\
\hline $\operatorname{BVAR}(3)$ & 1.662 & 1.669 & 1.707 & 1.649 & 0.799 & 0.848 & 0.875 & 0.868 \\
\hline $\operatorname{BVAR}(4)$ & 1.650 & 1.667 & 1.699 & 1.606 & 0.795 & 0.845 & 0.872 & 0.847 \\
\hline FAVAR(1) & 1.499 & 1.552 & 1.559 & 1.636 & 0.739 & 0.797 & 0.807 & 0.862 \\
\hline $\operatorname{FAVAR}(2)$ & 1.507 & 1.563 & 1.557 & 1.571 & 0.741 & 0.793 & 0.806 & 0.840 \\
\hline $\operatorname{FAVAR}(3)$ & 1.518 & 1.563 & 1.582 & 1.585 & 0.746 & 0.808 & 0.835 & 0.847 \\
\hline $\operatorname{FAVAR}(4)$ & 1.582 & 1.616 & 1.590 & 1.643 & 0.790 & 0.848 & 0.836 & 0.859 \\
\hline DSGE & 1.358 & 1.343 & 1.353 & 1.429 & 0.760 & 0.735 & 0.715 & 0.761 \\
\hline DSGE-VAR(1) & 1.538 & 1.685 & 1.689 & 1.663 & 0.748 & 0.840 & 0.864 & 0.882 \\
\hline DSGE-VAR(2) & 1.619 & 1.675 & 1.706 & 1.657 & 0.788 & 0.843 & 0.865 & 0.882 \\
\hline DSGE-VAR(3) & 1.528 & 1.654 & 1.635 & 1.629 & 0.756 & 0.822 & 0.833 & 0.870 \\
\hline DSGE-VAR(4) & 1.528 & 1.577 & 1.605 & 1.581 & 0.753 & 0.785 & 0.832 & 0.852 \\
\hline DSGE-FAVAR(1) & 1.524 & 1.585 & 1.597 & 1.657 & 0.747 & 0.807 & 0.825 & 0.878 \\
\hline DSGE-FAVAR $(2)$ & 1.499 & 1.571 & 1.605 & 1.652 & 0.739 & 0.793 & 0.825 & 0.879 \\
\hline DSGE-FAVAR(3) & 1.516 & 1.552 & 1.597 & 1.636 & 0.749 & 0.786 & 0.829 & 0.867 \\
\hline DSGE-FAVAR(4) & 1.435 & 1.498 & 1.571 & 1.565 & 0.713 & 0.774 & 0.819 & 0.835 \\
\hline TVP-VAR(1) & 1.484 & 1.415 & 1.368 & 1.375 & 0.793 & 0.778 & 0.748 & 0.740 \\
\hline TVP-VAR(2) & 1.644 & 1.608 & 1.412 & 1.438 & 0.943 & 0.868 & 0.773 & 0.777 \\
\hline TVP-VAR(3) & 1.851 & 1.618 & 1.461 & 1.549 & 1.159 & 0.846 & 0.825 & 0.818 \\
\hline TVP-VAR(4) & 1.979 & 1.598 & 1.310 & 1.437 & 1.212 & 0.850 & 0.763 & 0.788 \\
\hline
\end{tabular}

Notes: The out-of-sample (rolling) period is 2006:1-2010:4.

Next, the Diebold-Mariano (DM) pairwise test is employed in order to evaluate the comparative forecast accuracy. The results are reported in Tables 7, 8 and 9 in $p$-values. The Diebold-Mariano test is based on the squared prediction errors. The test has been conducted on the best performer of each model category, for each investigated macro-variable and forecast horizon. For example, in case of STN for the two-quarterahead forecasts, the DM test has been implemented pairwise on $\operatorname{VAR}(4), \operatorname{BVAR}(1), \operatorname{FAVAR}(4), \operatorname{DSGE}$, DSGE-VAR(2), DSGE-FAVAR(1) and TVP-VAR(4) model specifications, whilst for HICPSA for one-quarterahead forecasts the DM was applied on the VAR(1), BVAR(1), FAVAR(3), DSGE, DSGE-VAR(2), DSGEFAVAR(3) and TVP-VAR(4). The same logic applies for all variables and step-ahead forecast horizons. In accordance with previous empirical studies, the results are pairwise significantly different in many cases over four-quarters-ahead where deviations from linearities, large forecast errors and inherent uncertainties drive model predictions. The DM test statistics for YER indicate that none of the models consistently outperforms any of the other for one- and two-quarter-ahead forecasts, namely their pairwise forecast comparison shows no statistically significant difference. On the contrary, for four- and eight-steps ahead, differential predictability is significant at the $5 \%$ level for almost all forecasts of the VAR against the other models as well as for the DSGE pairs vs DSGE-VAR, DSGE-FAVAR and TVP-VAR. In particular, statistically significant scores are observed at $10 \%$ for BVAR vs DSGE-VAR, BVAR vs TVP-VAR, FAVAR vs DSGE, DSGE-VAR vs TVP-VAR and DSGE-FAVAR vs TVP-VAR and at the $1 \%$ for DGSE-VAR vs DSGE-FAVAR. These compared with the results from the MSFE and MAFE analysis show that the simple DSGE and TVP-VAR models outperform the other models, albeit this becomes more evident especially over the four-quarter-ahead forecasts. For the HICPSA series, the TVP-VAR in any pair shows a distinctively significant predictability at $1 \%$ in almost all 
Table 5: Mean Square Forecast Error (MSFE) and Mean Absolute Forecast Error (MAFE) scores for the Euro area CPI (HICPSA)

\begin{tabular}{|c|c|c|c|c|c|c|c|c|}
\hline \multirow{3}{*}{ HICPSA } & \multicolumn{4}{|c|}{ MSFE } & \multicolumn{4}{|c|}{ MAFE } \\
\hline & \multicolumn{4}{|c|}{ Quarters ahead } & \multicolumn{4}{|c|}{ Quarters ahead } \\
\hline & 1 & 2 & 4 & 8 & 1 & 2 & 4 & 8 \\
\hline $\operatorname{VAR}(1)$ & 0.506 & 0.511 & 0.484 & 0.588 & 0.634 & 0.583 & 0.553 & 0.650 \\
\hline $\operatorname{VAR}(2)$ & 0.607 & 0.524 & 0.587 & 0.567 & 0.691 & 0.591 & 0.643 & 0.626 \\
\hline $\operatorname{VAR}(3)$ & 0.826 & 0.562 & 0.685 & 0.606 & 0.792 & 0.630 & 0.709 & 0.650 \\
\hline $\operatorname{VAR}(4)$ & 0.685 & 0.573 & 0.601 & 0.420 & 0.700 & 0.637 & 0.641 & 0.533 \\
\hline $\operatorname{BVAR}(1)$ & 0.496 & 0.670 & 0.502 & 0.688 & 0.577 & 0.692 & 0.578 & 0.683 \\
\hline $\operatorname{BVAR}(2)$ & 0.534 & 0.848 & 0.531 & 0.750 & 0.619 & 0.781 & 0.582 & 0.734 \\
\hline $\operatorname{BVAR}(3)$ & 0.549 & 0.954 & 0.575 & 0.785 & 0.637 & 0.812 & 0.630 & 0.740 \\
\hline $\operatorname{BVAR}(4)$ & 0.612 & 0.924 & 0.585 & 0.776 & 0.692 & 0.806 & 0.641 & 0.753 \\
\hline $\operatorname{FAVAR}(1)$ & 0.561 & 0.558 & 0.553 & 0.627 & 0.642 & 0.623 & 0.589 & 0.663 \\
\hline $\operatorname{FAVAR}(2)$ & 0.636 & 0.510 & 0.583 & 0.554 & 0.712 & 0.599 & 0.633 & 0.624 \\
\hline $\operatorname{FAVAR}(3)$ & 0.558 & 0.555 & 0.580 & 0.566 & 0.655 & 0.631 & 0.638 & 0.622 \\
\hline FAVAR $(4)$ & 0.579 & 0.503 & 0.414 & 0.400 & 0.659 & 0.595 & 0.505 & 0.505 \\
\hline DSGE & 0.472 & 0.619 & 0.506 & 0.519 & 0.590 & 0.605 & 0.558 & 0.620 \\
\hline DSGE-VAR(1) & 0.713 & 0.511 & 0.480 & 0.574 & 0.726 & 0.581 & 0.550 & 0.645 \\
\hline DSGE-VAR $(2)$ & 0.564 & 0.497 & 0.537 & 0.541 & 0.671 & 0.578 & 0.607 & 0.613 \\
\hline DSGE-VAR(3) & 0.738 & 0.524 & 0.589 & 0.583 & 0.762 & 0.597 & 0.642 & 0.632 \\
\hline DSGE-VAR $(4)$ & 0.736 & 0.521 & 0.556 & 0.447 & 0.735 & 0.612 & 0.617 & 0.560 \\
\hline DSGE-FAVAR $(1)$ & 0.551 & 0.558 & 0.547 & 0.633 & 0.637 & 0.617 & 0.586 & 0.668 \\
\hline DSGE-FAVAR $(2)$ & 0.580 & 0.498 & 0.530 & 0.550 & 0.683 & 0.596 & 0.603 & 0.616 \\
\hline DSGE-FAVAR $(3)$ & 0.541 & 0.535 & 0.565 & 0.589 & 0.653 & 0.623 & 0.629 & 0.634 \\
\hline DSGE-FAVAR(4) & 0.568 & 0.488 & 0.404 & 0.455 & 0.665 & 0.594 & 0.511 & 0.557 \\
\hline TVP-VAR(1) & 0.561 & 0.499 & 0.518 & 0.529 & 0.590 & 0.598 & 0.603 & 0.612 \\
\hline $\operatorname{TVP}-\operatorname{VAR}(2)$ & 0.666 & 0.488 & 0.509 & 0.525 & 0.637 & 0.606 & 0.596 & 0.606 \\
\hline TVP-VAR(3) & 1.034 & 0.224 & 0.231 & 0.301 & 0.735 & 0.384 & 0.400 & 0.420 \\
\hline TVP-VAR(4) & 0.458 & 0.308 & 0.285 & 0.255 & 0.515 & 0.468 & 0.448 & 0.408 \\
\hline
\end{tabular}

Notes: As in Table 4

step-ahead forecasts. All statistics for all variables up to four-quarters-ahead appear to be insignificant even at the $10 \%$ level, with the exception of BVAR vs FAVAR and FAVAR vs DSGE-FAVAR. In accordance with the MSFE and MAFE results, it is evident that in case of HICPSA the TVP-VAR set-up outperforms the other models. Finally, in case of STN the DM results lead to a more diverse and variant assessment of differential predictability. While it appears that no particular model consistently and comparatively outperforms any of the other, yet the DSGE and the TVP-VAR present significant p-values in many pairwise comparisons. Specifically, the DSGE is superior when examined with the VARs, DSGE-VARs and DSGE-FAVARs and the TVP-VAR when compared to BVARs, FAVARs, DSGE-VARs and DSGE-FAVARs. Statistical significance varies in the previous examples from $5 \%$ to $1 \%$ in some cases, however it is not observed in two-quarterahead forecasts. Overall, many test statistics are not significant and the combined investigation of the MSFE, MAFE and DM results is not indicative of a clear outranking classification among the investigated models for all forecasting horizons, as was the case for the two other variables in the Euro area. 
Table 6: Mean Square Forecast Error (MSFE) and Mean Absolute Forecast Error (MAFE) scores for the Euro area Short-term Interest rate $(\mathrm{STN})$

\begin{tabular}{|c|c|c|c|c|c|c|c|c|}
\hline \multirow{3}{*}{ STN } & \multicolumn{4}{|c|}{ MSFE } & \multicolumn{4}{|c|}{ MAFE } \\
\hline & \multicolumn{4}{|c|}{ Quarters ahead } & \multicolumn{4}{|c|}{ Quarters ahead } \\
\hline & 1 & 2 & 4 & 8 & 1 & 2 & 4 & 8 \\
\hline $\operatorname{VAR}(1)$ & 1.461 & 2.100 & 2.817 & 7.041 & 1.117 & 1.356 & 1.540 & 2.220 \\
\hline $\operatorname{VAR}(2)$ & 0.891 & 1.836 & 4.814 & 10.899 & 0.555 & 0.951 & 1.552 & 2.683 \\
\hline $\operatorname{VAR}(3)$ & 0.907 & 1.753 & 4.284 & 9.580 & 0.701 & 1.054 & 1.532 & 2.539 \\
\hline $\operatorname{VAR}(4)$ & 1.261 & 1.706 & 3.801 & 7.386 & 0.999 & 1.093 & 1.517 & 2.273 \\
\hline $\operatorname{BVAR}(1)$ & 1.723 & 1.618 & 3.050 & 11.586 & 1.179 & 0.704 & 1.292 & 2.747 \\
\hline $\operatorname{BVAR}(2)$ & 0.794 & 3.469 & 4.421 & 13.843 & 0.654 & 1.264 & 1.328 & 3.046 \\
\hline $\operatorname{BVAR}(3)$ & 0.791 & 3.676 & 4.908 & 13.990 & 0.631 & 1.312 & 1.364 & 3.058 \\
\hline $\operatorname{BVAR}(4)$ & 0.794 & 3.193 & 4.796 & 12.527 & 0.620 & 1.153 & 1.346 & 2.865 \\
\hline $\operatorname{FAVAR}(1)$ & 1.029 & 1.486 & 3.030 & 6.655 & 0.803 & 0.882 & 1.211 & 2.134 \\
\hline $\operatorname{FAVAR}(2)$ & 1.402 & 2.299 & 4.945 & 9.505 & 0.887 & 1.034 & 1.472 & 2.504 \\
\hline FAVAR(3) & 1.225 & 1.771 & 3.541 & 7.903 & 0.817 & 0.904 & 1.252 & 2.299 \\
\hline FAVAR $(4)$ & 1.081 & 1.403 & 2.922 & 5.822 & 0.846 & 0.917 & 1.250 & 2.017 \\
\hline DSGE & 0.661 & 1.926 & 2.547 & 6.111 & 0.611 & 1.283 & 1.457 & 2.091 \\
\hline DSGE-VAR(1) & 0.852 & 1.950 & 2.780 & 7.009 & 0.765 & 1.300 & 1.518 & 2.205 \\
\hline DSGE-VAR(2) & 0.757 & 1.604 & 4.183 & 10.147 & 0.570 & 0.956 & 1.497 & 2.591 \\
\hline DSGE-VAR(3) & 0.816 & 1.645 & 3.990 & 9.364 & 0.525 & 1.024 & 1.489 & 2.504 \\
\hline DSGE-VAR(4) & 0.789 & 1.617 & 3.816 & 8.008 & 0.611 & 1.039 & 1.492 & 2.342 \\
\hline DSGE-FAVAR(1) & 1.135 & 1.708 & 3.485 & 7.553 & 0.779 & 0.896 & 1.266 & 2.255 \\
\hline DSGE-FAVAR(2) & 1.622 & 2.410 & 4.761 & 10.022 & 0.982 & 1.078 & 1.422 & 2.574 \\
\hline DSGE-FAVAR(3) & 1.561 & 2.429 & 4.962 & 9.551 & 0.950 & 1.076 & 1.439 & 2.525 \\
\hline DSGE-FAVAR(4) & 1.162 & 1.780 & 3.911 & 8.519 & 0.783 & 0.903 & 1.286 & 2.402 \\
\hline TVP-VAR(1) & 1.835 & 2.341 & 5.126 & 10.451 & 1.224 & 1.321 & 1.883 & 3.023 \\
\hline TVP-VAR(2) & 1.830 & 2.107 & 4.612 & 9.756 & 1.242 & 1.266 & 1.789 & 2.939 \\
\hline TVP-VAR(3) & 1.956 & 2.366 & 4.942 & 9.011 & 1.255 & 1.300 & 1.822 & 2.822 \\
\hline TVP-VAR(4) & 1.825 & 2.018 & 4.626 & 8.785 & 1.233 & 1.203 & 1.758 & 2.801 \\
\hline
\end{tabular}

Notes: As in Table 4

\section{Conclusions}

In recent years there has been a growing interest in the academia and central banks in micro-founded DSGE modelling. Policymakers are particularly interested in DSGE models as tools for estimation and evaluation. Moreover, increasing efforts have been undertaken to use these models for forecasting, although this proved to be problematic due to estimation and identification issues. Calibrated DSGE models are typically too stylized to be taken directly to the data, often yield weak prediction results and many times fail to capture the timeseries properties of the data. Very recently, hybrid or mixture models have become popular for dealing with some of the DSGE model misspecifications. Major advances in estimation methodology allowed these hybrid variants to compete in terms of data coherence, with more well-known time-series models, such as VARs. Even though VAR models and their various specifications such as Bayesian VARs and Factor Augmented VARs, have proven to be reliable forecasting tools, they are still linear and fail to take into account the inherent nonlinearities of the economy. Time-varying parameters seem to be attractive alternatives. In this paper, a time-varying multivariate state-space estimation method for VAR models has been presented. For the TVP-VAR model, the parameters are estimated using a multivariate specification of the standard Kalman filter (Harvey, 1990) combined with a suitable extension of the univariate methodology framework of Kim and Nelson (1999).

This study included a comparative evaluation of the out-of-sample predictive performance of many different specifications of estimated DSGE models and various classes of VAR models, using datasets for the real GDP, the harmonized Consumer Price Index and the nominal short-term Interest Rate series of the Euro area. Simple and hybrid DSGE models were implemented, such as DSGE-VARs and Factor Augmented DGSEs 
Table 7: Pairwise forecast comparison for the GDP (YER) with the Diebold-Mariano test

\begin{tabular}{|c|c|c|c|c|}
\hline \multirow[t]{2}{*}{ YER } & \multicolumn{4}{|c|}{ Quarters ahead } \\
\hline & 1 & 2 & 4 & 8 \\
\hline VAR vs BVAR & 0.168 & 0.226 & 0.721 & 0.213 \\
\hline VAR vs FAVAR & 0.120 & 0.208 & 0.011 & 0.002 \\
\hline VAR vs DSGE & 0.292 & 0.200 & 0.032 & 0.003 \\
\hline VAR vs DSGE-VAR & 0.101 & 0.129 & 0.013 & 0.002 \\
\hline VAR vs DSGE-FAVAR & 0.160 & 0.182 & 0.012 & 0.007 \\
\hline VAR vs TVP-VAR & 0.422 & 0.287 & 0.060 & 0.001 \\
\hline BVAR vs FAVAR & 0.130 & 0.159 & 0.038 & 0.006 \\
\hline BVAR vs DSGE & 0.273 & 0.182 & 0.047 & 0.009 \\
\hline BVAR vs DSGE-VAR & 0.123 & 0.072 & 0.069 & 0.003 \\
\hline BVAR vs DSGE-FAVAR & 0.160 & 0.149 & 0.045 & 0.003 \\
\hline BVAR vs TVP-VAR & 0.355 & 0.263 & 0.080 & 0.001 \\
\hline FAVAR vs DSGE & 0.402 & 0.194 & 0.054 & 0.001 \\
\hline FAVAR vs DSGE-VAR & 0.291 & 0.421 & 0.015 & 0.148 \\
\hline FAVAR vs DSGE-FAVAR & 0.256 & 0.116 & 0.163 & 0.436 \\
\hline FAVAR vs TVP-VAR & 0.853 & 0.359 & 0.105 & 0.000 \\
\hline DSGE vs DSGE-VAR & 0.364 & 0.225 & 0.041 & 0.002 \\
\hline DSGE vs DSGE-FAVAR & 0.497 & 0.218 & 0.049 & 0.006 \\
\hline DSGE vs TVP-VAR & 0.303 & 0.351 & 0.041 & 0.000 \\
\hline DSGE-VAR vs DSGE-FAVAR & 0.209 & 0.239 & 0.009 & 0.060 \\
\hline DSGE-VAR vs TVP-VAR & 0.692 & 0.368 & 0.077 & 0.001 \\
\hline DSGE-FAVAR vs TVP-VAR & 0.495 & 0.488 & 0.094 & 0.001 \\
\hline
\end{tabular}

Notes: The results are reported in p-values. The Diebold-Mariano $(1995)$ test based on squared prediction errors. The test has been conducted on the best performers of each category based on the MSE results.

Table 8: Pairwise forecast comparison for the CPI (HICPSA) with the Diebold-Mariano test

\begin{tabular}{lcccc}
\hline \hline HICPSA & \multicolumn{4}{c}{ Quarters ahead } \\
\cline { 2 - 5 } & 1 & 2 & 4 & 8 \\
\hline VAR vs BVAR & 0.728 & 0.302 & 0.742 & 0.003 \\
VAR vs FAVAR & 0.579 & 0.888 & 0.335 & 0.002 \\
VAR vs DSGE & 0.700 & 0.451 & 0.872 & 0.269 \\
VAR vs DSGE-VAR & 0.409 & 0.738 & 0.843 & 0.002 \\
VAR vs DSGE-FAVAR & 0.584 & 0.635 & 0.557 & 0.008 \\
VAR vs TVP-VAR & 0.688 & 0.001 & 0.001 & 0.004 \\
BVAR vs FAVAR & 0.627 & 0.162 & 0.001 & 0.001 \\
BVAR vs DSGE & 0.651 & 0.861 & 0.987 & 0.058 \\
BVAR vs DSGE-VAR & 0.514 & 0.194 & 0.769 & 0.001 \\
BVAR vs DSGE-FAVAR & 0.646 & 0.115 & 0.224 & 0.007 \\
BVAR vs TVP-VAR & 0.807 & 0.000 & 0.001 & 0.004 \\
FAVAR vs DSGE & 0.627 & 0.549 & 0.657 & 0.141 \\
FAVAR vs DSGE-VAR & 0.845 & 0.825 & 0.477 & 0.001 \\
FAVAR vs DSGE-FAVAR & 0.573 & 0.011 & 0.002 & 0.002 \\
FAVAR vs TVP-VAR & 0.072 & 0.001 & 0.005 & 0.000 \\
DSGE vs DSGE-VAR & 0.560 & 0.485 & 0.821 & 0.399 \\
DSGE vs DSGE-FAVAR & 0.627 & 0.494 & 0.908 & 0.459 \\
DSGE vs TVP-VAR & 0.947 & 0.004 & 0.087 & 0.002 \\
DSGE-VAR vs DSGE-FAVAR & 0.131 & 0.610 & 0.613 & 0.001 \\
DSGE-VAR vs TVP-VAR & 0.084 & 0.003 & 0.004 & 0.000 \\
DSGE-FAVAR vs TVP-VAR & 0.211 & 0.002 & 0.001 & 0.001 \\
\hline \hline Note As in Table 7 & & & &
\end{tabular}

Notes: As in Table 7 
Table 9: Pairwise forecast comparison for the Short-term Interest rate (STN) with the Diebold-Mariano test

\begin{tabular}{lcccc}
\hline \hline STN & \multicolumn{4}{c}{ Quarters ahead } \\
\cline { 2 - 5 } & 1 & 2 & 4 & 8 \\
\hline VAR vs BVAR & 0.712 & 0.890 & 0.839 & 0.001 \\
VAR vs FAVAR & 0.826 & 0.434 & 0.870 & 0.010 \\
VAR vs DSGE & 0.641 & 0.789 & 0.001 & 0.008 \\
VAR vs DSGE-VAR & 0.482 & 0.612 & 0.552 & 0.001 \\
VAR vs DSGE-FAVAR & 0.654 & 0.998 & 0.691 & 0.001 \\
VAR vs TVP-VAR & 0.212 & 0.131 & 0.274 & 0.002 \\
BVAR vs FAVAR & 0.627 & 0.761 & 0.047 & 0.002 \\
BVAR vs DSGE & 0.571 & 0.830 & 0.680 & 0.002 \\
BVAR vs DSGE-VAR & 0.676 & 0.974 & 0.804 & 0.001 \\
BVAR vs DSGE-FAVAR & 0.469 & 0.823 & 0.415 & 0.002 \\
BVAR vs TVP-VAR & 0.042 & 0.582 & 0.006 & 0.150 \\
FAVAR vs DSGE & 0.428 & 0.592 & 0.758 & 0.010 \\
FAVAR vs DSGE-VAR & 0.589 & 0.626 & 0.896 & 0.008 \\
FAVAR vs DSGE-FAVAR & 0.511 & 0.428 & 0.298 & 0.003 \\
FAVAR vs TVP-VAR & 0.292 & 0.187 & 0.002 & 0.001 \\
DSGE vs DSGE-VAR & 0.756 & 0.751 & 0.008 & 0.006 \\
DSGE vs DSGE-FAVAR & 0.366 & 0.867 & 0.593 & 0.001 \\
DSGE vs TVP-VAR & 0.004 & 0.915 & 0.229 & 0.000 \\
DSGE-VAR vs DSGE-FAVAR & 0.415 & 0.791 & 0.663 & 0.001 \\
DSGE-VAR vs TVP-VAR & 0.067 & 0.196 & 0.246 & 0.000 \\
DSGE-FAVAR vs TVP-VAR & 0.400 & 0.608 & 0.001 & 0.029 \\
\hline Note A In Tabl 7 & & & &
\end{tabular}

Notes: As in Table 7

(DSGE-FAVAR), and tested against standard VARs, Bayesian VARs, Factor Augmented VARs (FAVAR) and a time-varying parameter VAR model (TVP-VAR). The investigated period spanned from 1970:1 to 2010:4 with an out-of-sample testing period of 2006:1-2010:4, including the financial crisis of 2007-2009 and the EU debt crisis starting in early 2010, associated with the widening of bond yield spreads and the rise of credit default swaps for Eurozone countries. The results were evaluated with the use of mean squared and absolute forecast errors and varied across the three examined time series. The Diebold-Mariano (1995) pairwise test was also employed to measure comparatively the differential forecastability. The best forecasting performance for the harmonized Consumer Price Index was consistently produced by the TVP-VAR model, while for the GDP the simple DSGE outranked on average the other models. For the Interest Rate series, different models provided with the most accurate forecasts depending on the forecast horizon and the statistical measure of predictability used. In particular, FAVAR and the simple DSGE model were the best performers, whilst some BVAR and DSGE-VAR specifications provided with equally good forecasting results. The extensive empirical investigation and comparative model validation conducted in this study can be useful to monetary policy analysis and macro-forecasting in the Euro area. 


\section{References}

Adolfson M, Stefan L, Jesper L, Mattias V (2008) Evaluating an Estimated New Keynesian Small Open Economy Model, Journal of Economic Dynamics and Control, 32(8), 2690-2721

Altug S (1989) Time-to-Build and Aggregate Fluctuations: Some New Evidence, International Economic Review, 30(4), 889-920

Bai J., Ng S. (2000) Determining the Number of Factors in Approximate Factor Models, Econometrica, 70.

Benati L, Surico P (2009) VAR Analysis and the Great Moderation, American Economic Review, 99(4), $1636-52$

Bernanke B S., Boivin J. (2003) Monetary Policy in a Data-Rich Environment, Journal of Monetary Economics $50(3), 525-546$.

Bernanke B S., Boivin J. and Eliasz P. (2005) Measuring the Effects of Monetary Policy: A Factor-Augmented Vector Autoregressive (FAVAR) Approach, The Quarterly Journal of Economics, MIT Press, vol. 120(1), pages 387-422, January.

Boivin J, Giannoni MP (2006) DSGE Models in a Data-Rich Environment, NBER Working Papers 12772

Boivin J, Giannoni MP and Mihov I. (2009) Sticky Prices and Monetary Policy: Evidence from Disaggregated US Data, American Economic Review, American Economic Association, vol. 99(1), 350-84

Brüggemann R, H. Lütkepohl and M. Marcellino (2008) Forecasting euro area variables with German preEMU data, Journal of Forecasting, 27(6), 465-481

Canova F (1994) Statistical Inference in Calibrated Models, Journal of Applied Econometrics, 9, 123-144

Canova F, Gambetti L (2004) On the Time Variations of US Monetary Policy: Who is Right?, Money Macro and Finance (MMF) Research Group Conference.

Christiano, L. J., M. Eichenbaum, C. Evans (2005) Nominal Rigidities and the Dynamic effects of a Shock to Monetary Policy, Journal of Political Economy 113, 1-45.

Christoffel K, Günter C, Anders W (2008) The New Area-Wide Model of the Euro Area - A Micro-Founded Open-Economy Model for Forecasting and Policy Analysis, European Central Bank Working Paper Series n. 944

Chudik, A. and M. H. Pesaran (2009) Infinite Dimensional VARs and Factor Models, Working Paper Series 998, European Central Bank.

Clarida R, Galí J, Gertler M (2000) Monetary Policy Rules And Macroeconomic Stability: Evidence And Some Theory, The Quarterly Journal of Economics, 115(1), 147-180

Cogley TF, Sargent TJ (2005) Drift and Volatilities: Monetary Policies and Outcomes in the Post WWII U.S, Review of Economic Dynamics, 8(2), 262-302

Consolo A, Favero CA and Paccagnini A (2009) On the Statistical Identification of DSGE Models, Journal of Econometrics, 150, 99-115.

Dahlhaus R (1997) Fitting time series models to nonstationary processes, The Annals of Statistics, 25, 1-37

Dahlhaus R (2000) A likelihood approximation for locally stationary processes, The Annals of Statistics, 28, $1762-1794$

DeJong D, Ingram B, Whiteman C (1996) A Bayesian Approach to Calibration, Journal of Business Economics and Statistics, 14, 1-9

Del Negro M, Schorfheide F (2004) Priors from General equilibrium Models for VARs, International Economic Review, 45, 643-673 
Del Negro M, Schorfheide F, Smets F, Wouters R (2007) On the Fit of New-Keynesisan Models, Journal of Business, Economics and Statistics, 25(2), 124-162

Diebold FX, Mariano RS (1995) Comparing predictive accuracy, Journal of Business and Economic Statistics, 13(3), 253-263

Doan T, Litterman R, Sims C (1984) Forecasting and Conditional Projections Using Realistic Prior Distributions, Econometric Reviews, 3, 1-100

Dua P, Ray SC (1995) A BVAR model for the Connecticut Economy, Journal of Forecasting, 14(3), 167-180

Durbin J, Koopman SJ (2002) Time Series Analysis by State Space Methods, Oxford University Press

Fagan G., Henry J. and Mestre R. (2001) An area-wide model (AWM) for the euro area, Working Paper Series 42, European Central Bank.

Fernandez-Villaverde J (2009) The Econometrics of DSGE Models, NBER Working Paper 14677

Fernández-de-Córdoba G, Torres JL (2010) Forecasting the Spanish Economy with a DSGE Model: An Augmented VAR Approach, Journal of the Spanish Economic Association. Forthcoming

Forni M, Reichlin L. (1996): Dynamic Common Factors in Large Cross-Sections, Empirical Economics, 21, $27-42$.

Forni M, Reichlin L. (1998): Let's Get Real: A Dynamic Factor Analytical Approach to Disaggregated Business Cycle, Review of Economic Studies, 65, 453-474.

Forni M, Hallin M, Lippi M and Reichlin L. (1999): Reference Cycles: The NBER Methodology Revisited, mimeo.

Forni M, Hallin M, Lippi M and Reichlin L. (2000): The Generalized Dynamic-Factor Model: Identification And Estimation, The Review of Economic and Statistics, MIT Press, vol. 82(4), pages 540-554, November.

Geweke J (1999) Using Simulation Methods for Bayesian Econometric Models: Inference, Development and Communication, Econometric Reviews 18(1), 1-126

Ghent A (2009) Comparing DSGE-VAR Forecasting Models: How Big are the Differences?, Journal of Economic Dynamics and Control, 2009, 33(4), 864-882

Harvey AC (1990) Forecasting, structural time series and the Kalman filter, Cambridge University Press

Harvey AC (1986) Analysis and generalization of a multivariate exponential smoothing model, Management Science, 32, 374-380

Ingram B, Whiteman C (1994) Supplanting the Minnesota Prior - Forecasting Macroeconomics Time Series using Real Business Cycle Model Priors, Journal of Monetary Economics, 34, 497-510

Ireland P (2004) A Method for Taking Models to the Data, Journal of Economic Dynamics and Control, 28, $1205-1226$

Justiniano A, Primiceri GE (2008) The Time-Varying Volatility of Macro-economic Fluctuations, American Economic Review, 98(3), 604-41

Kadiyala KR, Karlsson S (1997) Numerical Methods for Estimation and Inference in Bayesian VAR-Models, Journal of Applied Econometrics, 12(2), 99-132

Kalman RE (1960) A New Approach to Linear Filtering and Prediction. Journal of Basic Engineering, Transactions of the ASME Series D 82, 35-45

Kalman RE (1963) New Methods in Wiener Filtering Theory. In: Bogdanoff J.L., Kozin F. (eds.) Proceedings of the First Symposium of Engineering Applications of Random Function Theory and Probability, Wiley, New York, 270-388 
Kim C-J, Nelson CR (1999) Has The U.S. Economy Become More Stable? A Bayesian Approach Based On A Markov-Switching Model Of The Business Cycle, The Review of Economics and Statistics, MIT Press, $81(4), 608-616$

Kim C-J, Nelson CR (1999) State space models with Regime switching, MIT Press

King RG (2000) The New IS-LM Model: Language, Logic, and Limits, Federal Reserve Bank of Richmond Economic Quarterly, 86, 45-103

Kolasa M, Rubaszek M, Skrzypczynski P (2009) Putting the New Keynesian DSGE Model to the Real-Time Forecasting Test, European Central Bank Working Paper Series n. 1110

Litterman RB (1981) A Bayesian Procedure for Forecasting with Vector Autoregressions, Working Paper, Federal Reserve Bank of Minneapolis

Litterman RB (1986) Forecasting with Bayesian Vector Autoregressions: Five Years of Experience, Journal of Business and Statistics 4(1), 25-38

Lubik TA, Schorfheide F (2004) Testing for Indeterminacy: An Application to U.S. Monetary Policy, American Economic Review, 94(1), 190-217

Marcellino, M. (2004) Forecasting EMU macroeconomic variables, International Journal of Forecasting, 20, $359-372$

Marcellino, M., J. H. Stock and M.W. Watson (2003) Macroeconomic forecasting in the Euro area: Country specific versus area-wide information, European Economic Review, 47(1), 1-18

McConnell MM, Perez-Quiros G (2000) Output Fluctuations in the United States: What Has Changed since the Early 1980's? American Economic Review, 90(5), 1464-1476

Prado G.H, West M (2001) Bayesian time-varying autoregressions: Theory, methods and applications. Resenhas Journal, 4, 405-422

Primiceri GE (2005) Time Varying Structural Vector Autoregressions and Monetary Policy, The Review of Economic Studies, 72, 821-852

Rubaszek M, Skrzypczynski P (2008) On the Forecasting Perfomance of a Small-Scale DSGE Model, International Journal of Forecasting, 24, 498-512

Sargent T (1989) Two Models of Measurements and the Investment Accelerator, Journal of Political Economy, $97(2), 251-287$

Schorfheide F (2010) Estimation and Evaluation of DSGE Models: Progress and Challenges, University of Pennsylvania

Schorfheide F, Sill K, Kryshko M (2010) DSGE Model-Based Forecasting of Non-Modelled Variables, International Journal of Forecasting, 26(2), 348-373

Sims CA (1980) Macroeconomics and reality, Econometrica, 48(1), 1-48

Sims, CA (2002) Solving Linear Rational Expectations Models, Computational Economics, 20 (1-2), 1-20

Sims CA, Zha T (1998) Bayesian Methods for Dynamic Multivariate Models, International Economic Review, $39,949-968$

Sims CA, Zha T (2006) Were There Regime Switches in U.S. Monetary Policy?, American Economic Review, $96(1), 54-81$

Smets F, Wouters R (2003) An Estimated Stochastic Dynamic General Equilibrium Model of the Euro Area, Journal of the European Economic Association, 1, 1123-1175 
Smets F, Wouters R (2004) Forecasting with a Bayesian DSGE model: an application to the Euro area, Working Paper No. 389, European Central Bank, Frankfurt

Spencer DE (1993) Developing a Bayesian Vector Autoregression Forecasting Model, International Journal of Forecasting 9(3), 407-421

Stock JH, Watson WM (2001) Vector autoregressions, Journal of Economic Perspectives, 15, 101-115

Stock JH, Watson WM (2002) Macroeconomic Forecasting Using Diffusion Indexe, Journal of Business Economics and Statistics, XX:II, 147-162.

Theil H, Goldberg AS (1961) On Pure and Mixed Estimation in Economics, International Economic Review, $2,65-78$

Todd RM (1984) Improving Economic Forecasting with Bayesian Vector Autoregression, Quarterly Review, Federal Reserve Bank of Minneapolis

Woodford M (2003) Interest and Prices, Princeton University Press

Zellner A (1963) Estimation for seemingly unrelated regression equations: some exact finite sample results, Journal of the American Statistical Association, 58, 977-992 


\section{Appendix}

The AWM database includes publicly available data produced by Eurostat and reported in the ECB Monthly Bulletin with a supplement for aggregated country data. The dataset consists of a panel of quarterly macroeconomic time series for the Euro Area (Fagan et al., 2001) spanning the period from 1970:1 to 2010:4. Data prior to 1996 are drawn from the last version of the AWM database, while the current version extends the series to 2010:4 with a fixed composition of the Euro area with 17 members. In the following Table, the first column has the series number, the second the series acronym, the third the series description, the fourth the transformation codes and the fifth column denotes a slow-moving variable with 1 and a fast-moving one with 0 . The transformed series are tested using the Box-Jenkins procedure and the Dickey-Fuller test. Following Bernanke et al. (2005), the transformation codes are as follows: 1 - no transformation; 2 - first difference; 4 - logarithm; 5 - first difference of logarithm; 6 - second difference; 7 - second difference of logarithm.

\begin{tabular}{|c|c|c|c|}
\hline Nr Acronym & Description & Tranformation & Slow $=1 /$ Fast $=0$ \\
\hline 1 CAN_YEN & Current Account Balance/GDP & 1 & 1 \\
\hline 2 COMPR & Commodity Prices & 5 & 0 \\
\hline 3 EEN & Effective exchange rate (EER12) & 2 & 0 \\
\hline 4 EXR & Euro per USD exhange rate & 2 & 0 \\
\hline $5 \mathrm{GCD}$ & Gov. Consumption Deflator & 6 & 1 \\
\hline $6 \mathrm{GCR}$ & Gov. Consumption & 7 & 1 \\
\hline 7 GON & Gross Operating Surplus & 5 & 1 \\
\hline $8 \mathrm{HEG}$ & HICP energy & 5 & 1 \\
\hline 9 HEGWEI & Weight of the HICP energy on overall HICP $(\mathrm{HICP}$ total $=1000)$ & 5 & 1 \\
\hline $10 \mathrm{HEX}$ & HICP excluding energy (Non-seasonally adjusted) & 7 & 1 \\
\hline 11 HEXSA & HICP excluding energy (Seasonally adjusted) & 7 & 1 \\
\hline $12 \mathrm{HICP}$ & Overall HICP (Non-sesonally adjusted) & 7 & 1 \\
\hline 13 HICPSA & Overall HICP (Seasonally adjusted) & 5 & 1 \\
\hline 14 ITD & Gross Investment Deflator & 6 & 1 \\
\hline 15 ITR & Gross Investment & 5 & 1 \\
\hline 16 LEN & Employees (persons) & 5 & 1 \\
\hline 17 LFN & Labour Force (persons) & 5 & 1 \\
\hline 18 LNN & Total Employment (persons) & 5 & 1 \\
\hline 19 LPROD & Labour Productivity (YER/LNN) & 5 & 1 \\
\hline 20 LTN & Long-Term Interest Rate & 5 & 0 \\
\hline $21 \mathrm{MTD}$ & Imports of Goods and Services Deflator & 2 & 1 \\
\hline 22 MTR & Imports of Goods and Services (Real) & 5 & 1 \\
\hline 23 NFN_YEN & Ratio, Net Factor Income from Abroad/GDP & 2 & 1 \\
\hline $24 \mathrm{PCD}^{-}$ & Consumption Deflator & 6 & 1 \\
\hline 25 PCOMU & Non oil commodity prices (in USD) & 5 & 0 \\
\hline 26 PCR & Private Consumption & 5 & 1 \\
\hline 27 POILU & Oil prices (in USD) & 5 & 0 \\
\hline $28 \mathrm{SAX}$ & Household's savings ratio & 2 & 1 \\
\hline 29 STN & Short-Term Interest Rate (Nominal) & 1 & 0 \\
\hline $30 \mathrm{TIN}$ & Indirect Taxes (net of subsidies) & 5 & 1 \\
\hline 31 ULC & Unit Labour Costs(WIN/YER) & 6 & 1 \\
\hline 32 UNN & Number of Unemployed & 5 & 1 \\
\hline 33 URX & Unemployment rate (as a percentage of labour force) & 2 & 1 \\
\hline 34 WIN & Compensation to Employees & 7 & 1 \\
\hline 35 WRN & Wage per head & 7 & 1 \\
\hline 36 XTD & Exports of Goods and Services Deflator & 2 & 1 \\
\hline $37 \mathrm{XTR}$ & Exports of Goods and Services (Real) & 5 & 1 \\
\hline 38 YED & GDP Deflator & 6 & 1 \\
\hline 39 YER & GDP (Real) & 5 & 1 \\
\hline 40 YFD & GDP at Factor Costs Deflator & 7 & 1 \\
\hline 41 YFN & GDP at Factor Costs (WIN+GON) & 5 & 1 \\
\hline $42 \mathrm{YIN}$ & GDP, Income Side & 5 & 1 \\
\hline 43 YWD & World GDP Deflator & 7 & 1 \\
\hline 44 YWDX & World Demand Deflator, Composite Indicator & 5 & 1 \\
\hline 45 YWR & World GDP & 5 & 1 \\
\hline 46 YWRX & World Demand, Composite Indicator & 5 & 1 \\
\hline
\end{tabular}

